\title{
The nomenclature, definition and classification of hypoplastic left heart syndrome
}

Christo I. Tchervenkov, ${ }^{1}$ Jeffrey P. Jacobs, ${ }^{2}$ Paul M. Weinberg, ${ }^{3}$ Vera D. Aiello, ${ }^{4}$ Marie J. Béland, ${ }^{5}$ Steven D. Colan, ${ }^{6}$ Martin J. Elliott, ${ }^{7}$ Rodney C.G. Franklin, ${ }^{8}$ J. William Gaynor, ${ }^{9}$ Otto N. Krogmann, ${ }^{10}$ Hiromi Kurosawa, ${ }^{11}$ Bohdan Maruszewski, ${ }^{12}$ Giovanni Stellin ${ }^{13}$

${ }^{1}$ Division of Pediatric Cardiovascular Surgery, The Montreal Children's Hospital of the McGill University Health Centre, Montréal, Quebec, Canada; ${ }^{2}$ Congenital Heart Institute of Florida (CHIF), Division of Thoracic and Cardiovascular Surgery, All Children's Hospital/Children's Hospital of Tampa, University of South Florida College of Medicine, Cardiac Surgical Associates, St-Petersburg, Florida, United States of America; ${ }^{3}$ Division of Pediatric Cardiology, The Children's Hospital of Philadelphia, Pennsylvania, United States of America; ${ }^{4}$ Heart Institute (InCor), Sao Paulo University School of Medicine, Sao Paulo, Brazil; ${ }^{5}$ Division of Pediatric Cardiology, The Montreal Children's Hospital of the McGill University Health Centre, Montréal, Quebec, Canada; ${ }^{6}$ Department of Cardiology, Children's Hospital, Boston, Massachusetts, United States of America; ${ }^{7}$ Cardiac Unit, Great Ormond Street Hospital for Children, London, United Kingdom; ${ }^{8}$ Paediatric Cardiology Directorate, Royal Brompton \& Harefield NHS Trust, Harefield, Middlesex, United Kingdom; ${ }^{9}$ Cardiac Surgery, Children's Hospital of Philadelphia, Philadelphia, Pennsylvania, United States of America; ${ }^{10}$ Paediatric Cardiology - CHD, Heart Center Duisburg, Duisburg, Germany; ${ }^{11}$ Cardiovascular Surgery, Heart Institute of Japan; Tokyo Women's Medical University, Tokyo, Japan; ${ }^{12}$ The Children's Memorial Health Institute, Department of Cardiothoracic Surgery, Warsaw, Poland;

${ }_{13}$ Pediatric Cardiac Surgery Unit - University of Padova Medical School, Padova, Italy

Abstract The hypoplastic left heart syndrome encompasses a spectrum of cardiac malformations that are characterized by significant underdevelopment of the components of the left heart and the aorta, including the left ventricular cavity and mass. At the severe end of the spectrum is found the combination of aortic and mitral atresia, when the left ventricle can be close to non-existent. At the mild end are the patients with hypoplasia of the aortic and mitral valves, but without intrinsic valvar stenosis or atresia, and milder degrees of left ventricular hypoplasia. Although the majority of the patients are suitable only for functionally univentricular repair, a small minority may be candidates for biventricular repair.

The nature of the syndrome was a topic for discussion at the second meeting of the International Working Group for Mapping and Coding of Nomenclatures for Paediatric and Congenital Heart Disease, the Nomenclature Working Group, held in Montreal, Canada, over the period January 17 through 19, 2003. Subsequent to these discussions, the Nomenclature Working Group was able to create a bidirectional crossmap between the nomenclature initially produced jointly on behalf of the European Association for Cardio-Thoracic Surgery and the Society of Thoracic Surgeons, and the alternative nomenclature developed on behalf of the Association for European Paediatric Cardiology. This process is a part of the overall efforts of the Nomenclature Working Group to create a comprehensive and all-inclusive international system of nomenclature for paediatric and congenital cardiac disease, the International Paediatric and Congenital Cardiac Code. In this review, we discuss the evolution of nomenclature and surgical treatment for the spectrum of lesions making up the hypoplastic left heart syndrome and its related malformations. We also present the crossmap of the associated terms for diagnoses and procedures, as recently completed by the Nomenclature Working Group.

Keywords: Classification; databases; hypoplasia of the left heart

Correspondence to: Christo I. Tchervenkov MD, Division of Cardiovascular Surgery, The Montreal Children's Hospital, McGill University 2300 Tupper - C-829 Montréal, Québec, Canada H3H 1P3. Tel: +514 412 4400, Ext. 22394; Fax: +514 412 4330; E-mail: christo.tchervenkov@muhc.mcgill.ca

Accepted for publication 3 February 2006 
$\mathrm{T}$ HE HYPOPLASTIC LEFT HEART SYNDROME describes a heterogeneous group of cardiac malformations consisting of various degrees of underdevelopment of the left heart and the aorta, resulting in significant obstruction to flow of blood into the systemic circulation, and difficulty in the left heart supporting adequately this circulation. In the past, precise definitions for the syndrome have been lacking, and the term has been used interchangeably with a variety of others, creating not only varying degrees of confusion, but also lack of consistency in usage. In 2000, Tchervenkov, Jacobs and Tahta, on behalf of the International Congenital Heart Surgery Nomenclature and Database Project, proposed a definition and provided a classification for the hypoplastic left heart syndrome. ${ }^{1}$ The topic had been the subject of extensive debates and review during the meetings of members of the Society of Thoracic Surgeons and the European Association for Cardio-Thoracic Surgery, which took place over the period 1998 through 2000 as part of the International Congenital Heart Surgery Nomenclature and Database Project. ${ }^{1}$ Efforts were made to include all relevant categories of nomenclature, using synonyms where appropriate. The topic was further debated at the second meeting of the International Working Group for Mapping and Coding of Nomenclatures for Paediatric and Congenital Heart Disease, also known as the Nomenclature Working Group, ${ }^{2-7}$ which was held in Montreal, Canada, over the period January 17 through 19, 2003. It has been the task of the Nomenclature Working Group to establish the International Paediatric and Congenital Cardiac Code. This task has been achieved by reviewing 28 major categories of cardiac lesions, and crossmapping several existing systems for nomenclature, including that prepared on behalf of the European Association for Cardio-Thoracic Surgery and the Society of Thoracic Surgeons, and the alternative version prepared for the Association for European Paediatric Cardiology. ${ }^{2-7}$ This International Paediatric and Congenital Cardiac Code was unveiled officially during the Second International Summit on Nomenclature for Paediatric and Congenital Heart Disease, held at the Fourth World Congress of Paediatric Cardiology and Cardiac Surgery in Buenos Aires, Argentina, on September 19, 2005 [www.ipccc.net].

In this article, we will refer to the International Paediatric and Congenital Cardiac Code as the International Code and we will present two versions of this International Code for diagnoses and procedures related to hypoplastic left heart syndrome and related malformations:

- The version of the International Code derived from the nomenclature of the International Congenital Heart Surgery Nomenclature and Database Project of the European Association for Cardio-Thoracic Surgery and the Society of Thoracic Surgeons

- The version of the International Code derived from the nomenclature of the European Paediatric Cardiac Code of the Association for European Paediatric Cardiology.

Both of these systems were developed with considerable input from both cardiologists and surgeons. It is the crossmap developed for diagnoses and procedures related to hypoplastic left heart syndrome and related malformations that will be the focus of this article. So as to set the scene, however, we summarize the historical aspects of terminology, the early development of surgical treatment, and the current nomenclature, definition, and classification of hypoplastic left heart syndrome. In this respect, the current imperative of the Nomenclature Working Group is to provide a classification of cardiac phenotypes, and not genotypes. In the future, knowledge of the underlying genetic defects may modify the schemes currently developed for classification. Multiple genotypes may lead to the same phenotype. Genotypic analysis may alter not only the schemes used for classification, but also therapies and outcomes.

\section{Historical perspectives on nomenclature for the hypoplastic left heart syndrome}

As far as we can establish, the initial description of the pathophysiology of hypoplastic left heart syndrome, describing the combination of severe mitral and left ventricular hypoplasia along with aortic atresia, was elegantly written in German by Bardeleben in 1851. This contribution has recently been translated into English by Gehrmann et al. ${ }^{8}$ A century later, in 1952, the tendency of hypoplastic and obstructive lesions of the left heart and aorta to occur together was emphasized by Maurice Lev. ${ }^{9}$ He used the term "hypoplasia of the aortic tract complexes" to describe these heterogeneous malformations. The anatomic features attracting his attention were:

- the ascending and transverse portions of the aorta and the aortic orifice were small;

- the pulmonary trunk and its orifice were large;

- there was no transposition of the arterial trunks.

In terms of physiology, he emphasized the decrease of flow through the components of the left heart and the aorta, with concomitant increase in right ventricular flow. Based on the examination of 40 pathologic hearts, he classified his suggested complexes as follows:

- isolated hypoplasia of the aorta;

- hypoplasia of the aorta with septal defects; 
- hypoplasia of the aorta with aortic atresia or stenosis without mitral atresia;

- hypoplasia of the aorta with aortic atresia or stenosis with mitral atresia.

In $1966,{ }^{10}$ he narrowed his classification to, on the one hand, severe aortic stenosis or atresia with a patent mitral valve, and on the other hand, the combination of aortic and mitral atresia. After a further extensive period of review, and having examined 230 hearts, Bharati and Lev ${ }^{11}$ maintained this classification of hypoplasia of the aortic tract complexes.

In the meantime, however, in 1958, the term "hypoplastic left heart syndrome" had been suggested by Noonan and Nadas ${ }^{12}$ to include anomalies with an obstructive lesion on the left side of the heart. Their original definition was broad, including lesions ranging from aortic and mitral atresia with a vestigial left ventricle, to milder forms of left ventricular underdevelopment. They noted that the clinical syndrome could be caused by several pathological complexes. Based on the analysis of 101 postmortem hearts, they subclassified five groups, specifically

- aortic valvar atresia;

- mitral atresia;

- mitral stenosis;

- atresia of the aortic arch;

- hypoplasia of the aortic arch.

Interestingly, the last group was by far the largest, and included 71 cases. All these cases shared similarities in their clinical presentation. Noonan and Nadas $^{12}$ suggested that diagnosis of the syndrome should be suspected in the presence of sudden onset of biventricular congestive heart failure in a young infant with mild cyanosis, a nonspecific heart murmur, and either weak pulses in all extremities, or relative hypertension in the arm. Although the clinical recognition of the syndrome, in most cases, was not difficult, the precise pre-mortem anatomic diagnosis was usually impossible because of the limited modalities for cardiac imaging existing at that time.

Shortly after the appearance of the stellar review from Noonan and Nadas, ${ }^{12}$ Currarino and associates, ${ }^{13}$ in 1959 , used the term "hypoplasia of the left heart complex" to describe the pathologic findings in two neonates who exhibited aortic and mitral stenosis, hypoplasia of the left ventricle with endocardial fibroelastosis, and a hypoplastic aorta from its origin until the insertion of the arterial duct. Both patients, who had died in the first week of life, exhibited differential cyanosis, with a pink right upper quadrant of the trunk, the right side of the head and neck and the right arm, with the rest of the body being cyanotic. Both patients had complete obliteration of the oval foramen, believed by some to be implicated in the aetiology of this complex by causing deranged patterns of flow during fetal life.

Over the ensuing decades, despite its lack of specificity and consistent definition, the term "hypoplastic left heart syndrome" has become the one most widely accepted and currently used in the English language. This reality could be explained by the fact that Norwood et al., ${ }^{14,15}$ along with Doty et al., ${ }^{16}$ used this term in their early reports proposing options for surgical treatment. From the beginning, nonetheless, there has been controversy as to what makes up the hypoplastic left heart syndrome. For some, the syndrome was defined in narrow terms, such as atresia of the aortic or mitral valve, or both, with normally related great arteries and intact ventricular septum, and was held to include only cases with a small left ventricle clearly incapable of supporting the systemic circulation. ${ }^{17}$ Others preferred a more general definition of underdevelopment, such as atresia or hypoplasia of the left atrial outlet, left ventricle, aortic valve, and aortic arch. ${ }^{18}$ Their argument was to avoid focusing attention on the hopeless forms of hypoplastic left heart syndrome, but rather to emphasize that nearly one half of the cases were salvageable by intensive medical management and surgical palliation.

It was the search for a suitable surgical treatment that culminated, in the 1980s, in the development of both the Norwood operation and neonatal transplantation of the heart. Unfortunately, in the early days, the term "Norwood operation" tended to be used as a synonym for the syndrome itself, implying the inability of the left heart to support the systemic circulation. The more recent application of the Norwood operation for lesions such as tricuspid atresia with discordant ventriculo-arterial connections, or hearts with two well-developed ventricles in which biventricular repair is either difficult or impossible, such as some forms of double outlet right ventricle with non-committed ventricular septal defect, hearts with straddling atrioventricular valves, and severely unbalanced atrioventricular septal defects, has shown that use of the term "Norwood operation" no longer implies the diagnosis of hypoplastic left heart syndrome. ${ }^{19-21}$ The diagnosis of the syndrome, therefore, should not be defined by the use of the Norwood operation to repair it.

It was, perhaps, the resulting lack of specificity for the syndrome that led Kirklin and BarrattBoyes $^{22}$ to use the term with a still wider meaning. They proposed a classification based on the number of obstructions in the left heart and aorta. Their first and second classes were made up of patients with one and two obstructions, respectively. Their third class 
included those with more than two obstructions together with left ventricular hypoplasia, while their fourth class was made up of the patients with aortic atresia. The use of this classification of hypoplastic left heart syndrome as defined by Kirklin and Barratt-Boyes, however, is impractical, since it lacks specificity, requiring a further specific definition in each individual case. This requirement defeats the purpose of the diagnosis. Furthermore, many would not routinely use the term hypoplastic left heart syndrome to describe those patients making up the first two classes, but rather prefer the specific diagnoses, such as aortic stenosis, coarctation of the aorta, or interruption of the aortic arch. On the other hand, when dealing with the severe form, the opposite is true, with the term hypoplastic left heart syndrome being used frequently to lump together several diagnoses that have in common a right ventriculardependent systemic circulation, such as aortic atresia, mitral atresia with aortic stenosis, or mitral stenosis with severe left ventricular hypoplasia. Even though the classification proposed by Kirklin and BarrattBoyes $^{22}$ is impractical, and has not gained widespread use and acceptance, it does convey the crucial concept that hypoplastic left heart syndrome is a spectrum of malformations.

It is also a fact that, although the term "hypoplastic left heart syndrome" was originally used by Noonan and Nadas ${ }^{12}$ to describe a range of anomalies including multiple levels of obstruction within the left heart and the aortic pathways, patients with hypoplasia of the left ventricle with aortic and mitral valves which are hypoplastic but not intrinsically stenotic have been inadequately and inconsistently described within the currently existing terminology. ${ }^{23-28}$ For this reason, in 1998, Tchervenkov and associates ${ }^{29}$ introduced the term "hypoplastic left heart complex" to describe the patients with significant hypoplasia of the structures of the left heart and aorta, but in the absence of intrinsic stenosis or atresia of the aortic and mitral valves. Although Currarino and associates ${ }^{13}$ had previously used the similar, but slightly different, term "hypoplasia of the left heart complex", they had used it for patients with valvar aortic stenosis, and not for the cardiac phenotype of hypoplasia of the left heart without intrinsic valvar stenosis or atresia as described by Tchervenkov and associates. ${ }^{1,29}$ The term, "hypoplastic left heart complex", was accepted and incorporated into the nomenclature published by the International Congenital Heart Surgery Nomenclature and Database Project in 2000 , being used to account for the cardiac phenotype at the milder end of the spectrum of hypoplastic left heart syndrome, but without intrinsic aortic or mitral valvar stenosis or atresia. ${ }^{1}$ In this respect, it is also of note that, in the review made by Noonan and Nadas, ${ }^{12}$ their largest group of patients was made up of those with isolated hypoplasia of the aortic arch. These patients had a small but functioning left ventricle. It is likely that many of the patients in this group would nowadays fall within the diagnosis of the hypoplastic left heart complex. Although patients with the complex also bear some similarities to another developmental complex, namely that described by Shone and associates, ${ }^{30}$ the two diagnoses are distinct, and should not be used interchangeably. The report of Shone et al., ${ }^{30}$ based on analysis of 8 autopsied cases, described the tendency for four obstructive, or potentially obstructive, conditions to coexist. These were:

- supravalvar ring of the left atrium;

- a parachute deformity of the mitral valve;

- subaortic stenosis;

- aortic coarctation.

Only 2 of the 8 cases exhibited all four conditions, with the other cases exhibiting only two or three of the anomalies. Hypoplasia of the various components of the left heart and aorta, a fundamental feature of hypoplastic left heart complex, was not present in the patients described in the account of Shone et al. ${ }^{30}$ Hypoplastic left heart complex, therefore, is part of the spectrum of hypoplastic left heart syndrome, whereas Shone's complex is not.

The overwhelming majority of patients with hypoplastic left heart syndrome have an intact ventricular septum. If there is a ventricular septal defect, it is usually small. When a large ventricular septal defect co-exists with aortic atresia, the left ventricle is usually well-developed. In a review of 172 patients with aortic atresia, ${ }^{31} 12$ patients $(7 \%)$ were found to have a large ventricular septal defect with a welldeveloped left ventricle. These patients obviously should not be classified as part of the hypoplastic left heart syndrome. In his classic report on palliative surgery for hypoplastic left heart syndrome, describing the management of three patients, Norwood and associates used the term "aortic atresia with intact ventricular septum" to distinguish the common forms of hypoplastic left heart syndrome from their one case of aortic atresia with ventricular septal defect. ${ }^{14}$ Unfortunately the terms "aortic atresia with intact ventricular septum", and "aortic atresia with ventricular septal defect", have not found favour to the same extent as "pulmonary atresia with intact ventricular septum" and "pulmonary atresia with ventricular septal defect", probably due to the rarity of the patients with aortic atresia and a large ventricular septal defect. Nevertheless, in the system of nomenclature prepared by the International Congenital Heart Surgery Nomenclature and Database Project, cases with aortic 
atresia and ventricular septal defect were included under the grouping for hypoplastic left heart syndrome because of the inability to group them with any other congenital lesion. Recognising the potential deficiency in this approach, the chosen grouping is discussed further in the last paragraph in the next section of this manuscript titled "Definition of Hypoplastic Left Heart Syndrome". In the International Pediatric and Congenital Cardiac Code, the lesion "aortic atresia with ventricular septal defect and a well-developed mitral valve and left ventricle" is not classified as hypoplastic left heart syndrome, but rather as a "hypoplastic left heart syndromerelated malformation", specifically because the problematic lesion does not include significant hypoplasia of the left ventricle, this being an essential element of hypoplastic left heart syndrome.

We should then note that the term "hypoplastic left heart physiology" was introduced in 2003 , in the third edition ${ }^{32}$ of the textbook devoted to cardiac surgery initially written by Kirklin and Barratt-Boyes. This proposed entity was defined as "the inability of the left heart to sustain an adequate cardiac output following birth because of underdevelopment of one or more left heart structures despite surgical or medical intervention". ${ }^{32}$ Although the editors of the textbook chose the term "hypoplastic left heart physiology", rather than the more common and entrenched term "hypoplastic left heart syndrome", they pointed out important limitations of both terms when applied in the clinical setting because "tests designed to define morphologic and physiologic characteristics are limited in their ability". A problem with putting the emphasis on physiology, however, is that physiology can change over a short period of time through a multitude of factors. On the other hand, if classification is based on anatomic and morphologic features, these factors change much more slowly.

\section{Definition of hypoplastic left heart syndrome}

Before proceeding further, we consider it useful to provide definitions ${ }^{33}$ of several terms pertinent to the ongoing discussion of the term "hypoplastic left heart syndrome". These are
- atresia
- stenosis
- hypoplasia
- obstruction
- syndrome
- complex

"Atresia" is defined as the congenital absence or closure of a normal body orifice or tubular organ. It is derived from the Greek and Latin bases, where "a" means without, and "tresis" is the word for perforation. Thus, aortic valvar atresia can be defined as either absence or closure of the orifice of the aortic root.

"Stenosis" is narrowing or stricture of a duct or a canal. Aortic stenosis, for example, is a broad term encompassing the supravalvar, valvar or subvalvar variants. More specifically, aortic valvar stenosis is a narrowing of the orifice of the aortic valve due to fusion of the zones of apposition between the leaflets, or the inability of the valve to open adequately because of thickening or calcification of the leaflets, causing obstruction to the flow of blood.

"Hypoplasia" is the incomplete development or underdevelopment of an organ or tissue. For example, a hypoplastic aortic valve can cause obstruction to the flow of blood simply because of its inadequate size.

"Obstruction" is the act of blocking or clogging, or the state or condition of being blocked or clogged. Obstruction to the flow of blood, therefore, may be caused by atresia, stenosis, or hypoplasia of a given structure.

We consider it particularly important to differentiate the meaning of the terms "stenosis" and "hypoplasia". Although atresia and stenosis are mutually exclusive terms, hypoplasia may be present with atresia or stenosis, or can exist in isolation. Hypoplasia implies that the organ or tissue is less than its normal size. The terms "aortic stenosis" and "left ventricular outflow tract obstruction", for example, are not synonymous, although they have been used interchangeably in the past. In the setting of obstruction to the left ventricular outflow tract, the obstruction to the flow of blood may be caused by either aortic atresia, aortic stenosis, or because of hypoplasia of the aortic valve.

A "syndrome" is a group of signs and symptoms that occur together, and characterize a particular abnormality.

A "complex" is a whole, being made up of interrelated parts.

During its many meetings, the members of the International Congenital Heart Surgery Nomenclature and Database Project thoroughly debated the term and definition of "hypoplastic left heart syndrome". Initially, enthusiasm existed for not using the term "hypoplastic left heart syndrome". Arguments were made to discard the term in favour of specific definitions of the exact anatomy. Thought was given to utilization of the terms "Aortic atresia with ventricular septal defect" and "Aortic atresia with intact ventricular septum", as well as the descriptive terms:

Aortic atresia and mitral atresia

- Aortic atresia and mitral stenosis

- Aortic stenosis and mitral atresia 
- Aortic stenosis and mitral stenosis

- Combined aortic and mitral valvar hypoplasia

Initial thoughts to discard the term "hypoplastic left heart syndrome" eventually gave way to a consensus to retain the term, but then to define it. This decision was reached after many hours of debate for multiple reasons:

- The descriptive terms listed above fail to convey that the common denominator of this lesion is hypoplasia of the left heart and ventricle.

- The term "hypoplastic left heart syndrome" has widespread use and acceptance in the medical community, as emphasized by its appearance in no less than 1109 articles in a PubMed MedLine Search with the United States National Library of Medicine from November 1958 through November 2005.

- It seems unlikely that this term will disappear because of the work of the International Congenital Heart Surgery Nomenclature and Database Project, the Nomenclature Working Group, or any other governing body.

- Given that the term will still be used, a unifying definition and subclassification should be proposed. Otherwise, it will continue to be used without a common definition.

- It is useful to group together the subtypes of lesions considered to represent the "hypoplastic left heart syndrome". This grouping can facilitate the analysis of outcomes, and does not prohibit further anatomic description of the subtypes.

- Description and definition of the subtypes is still possible and desirable, even with retention of the term "hypoplastic left heart syndrome".

Thus, when their work was published in the supplement of Annals of Thoracic Surgery appearing in April, 2000, ${ }^{1}$ the International Congenital Heart Surgery Nomenclature and Database Project retained, defined, and subclassified the term "hypoplastic left heart syndrome". It is a modification of this definition that is suggested currently by the Nomenclature Working Group, as will be shown below.

We may also argue, however, as why to use the word "syndrome" at all. For example, in the French language, the term in common use is "hypoplasie du coeur gauche", a phrase that avoids the use of "syndrome". On this basis, an alternative would be to replace the term "hypoplastic left heart syndrome" with "hypoplasia of the left heart". This proposal is further strengthened by the belief that the genetic community defines a "syndrome" as a constellation of anomalies afflicting multiple systems of organs. There are, nonetheless, several other definitions of "syndrome", even within the genetic community. According to Dorland's Illustrated Medical Dictionary, ${ }^{33}$ a syndrome is "in genetics, a pattern of multiple malformations thought to be pathogenetically related". This definition, in a very respectable and well-read medical dictionary, makes no mention of the concept that a syndrome should involve multiple systems of organs. Furthermore, Dorland's Illustrated Medical Dictionary then goes on to list and define several pages of a variety of medical syndromes, some of which involve multiple systems of organs, but others which involve only a single system of organs. Thus, even the genetic definition of "syndrome" is not universally accepted.

In the light of their discussions, the Nomenclature Working Group took the stance that the terms "hypoplastic left heart syndrome" and "hypoplasia of the left heart" would better be used as synonyms, since there is no scientific justification exclusively to use one term and eliminate the other. On this basis, therefore, the Nomenclature Working Group offers the following definition for the term "hypoplastic left heart syndrome" or "hypoplasia of the left heart":

"Hypoplastic left heart syndrome is synonymous with the term hypoplasia of the left heart and is defined as a spectrum of cardiac malformations with normally aligned great arteries without a common atrioventricular junction, characterized by underdevelopment of the left heart with significant hypoplasia of the left ventricle including atresia, stenosis, or hypoplasia of the aortic or mitral valve, or both valves, and hypoplasia of the ascending aorta and aortic arch."

Hypoplastic left heart syndrome, therefore, is made up of several pathological cardiac phenotypes. At the severe end of the spectrum are found those patients with aortic and mitral atresia with a virtually nonexistent left ventricle. The heart with a truly nonexistent ventricle is extremely rare, and indeed may not exist, as typically it is possible at autopsy to identify some small, incomplete, and hypoplastic ventricle that lacks an atrioventricular connection. At the milder end of the spectrum are those patients with hypoplastic left heart syndrome without intrinsic valvar stenosis or atresia, this representing the hypoplastic left heart complex as defined by Tchervenkov et al., ${ }^{29}$ or those patients with critical aortic stenosis and left ventricular hypoplasia. ${ }^{34,35}$ Patients with critical aortic stenosis with left ventricles and mitral valves of normal size, however, are not considered as comprising part of the hypoplastic left heart syndrome.

On this basis, we offer a definition of hypoplastic left heart syndrome without intrinsic valvar stenosis or atresia as follows:

"Hypoplastic left heart syndrome without intrinsic valvar
stenosis or atresia is synonymous with the term hypoplastic left 
heart complex and is defined as a cardiac malformation at the milder end of the spectrum of hypoplastic left heart syndrome with normally aligned great arteries without a common atrioventricular junction, characterized by underdevelopment of the left heart with significant hypoplasia of the left ventricle and hypoplasia of the aortic or mitral valve, or both valves, in the absence of intrinsic valvar stenosis or atresia, and with hypoplasia of the ascending aorta and aortic arch."

In other words, hypoplastic left heart complex is a cardiac malformation at the milder end of the spectrum of hypoplastic left heart syndrome without intrinsic stenosis or atresia of the aortic or mitral valve. We recognize that the term "hypoplastic left heart complex" has not yet gained widespread acceptance, and has been found confusing by some. Because of this, other terms have been suggested to describe patients with hypoplasia of the left heart without intrinsic aortic or mitral valve stenosis or atresia, such as "hypoplastic left heart syndrome without intrinsic valvar stenosis or atresia" and "hypoplasia of the left heart without intrinsic valvar stenosis or atresia".

The differentiation of the proposed complex from the other subtypes of hypoplastic left heart syndrome is based on identification of hypoplasia of the left heart in absence of intrinsic aortic or mitral valvar stenosis or atresia. ${ }^{29}$ It remains the case that differentiation between patients to be grouped within the complex as opposed to the other cardiac phenotypes within the syndrome itself can be difficult. The terms "Aortic stenosis" and "Mitral stenosis" infer that there is fusion between the zones of apposition of the valvar leaflets, and hence true valvar stenosis. Hypoplasia of the aortic valve, mitral valve and the left ventricle, in contrast, indicates that the valves are small, but not intrinsically stenotic. This differentiation has therapeutic considerations and potential consequences if one considers biventricular repair. While aortic valvotomy is essential in patients with critical valvar aortic stenosis and left ventricular hypoplasia that are candidates for biventricular repair, it is not required in patients appropriately diagnosed as having hypoplastic left heart complex, because the aortic valve in the setting of the complex, whilst hypoplastic, is not intrinsically stenotic.

Another area of potential controversy regards the relationship between the hypoplastic left heart complex as defined by us, and totally anomalous pulmonary venous connection. In this respect, it should be remembered that, just as hypoplastic left heart syndrome with aortic atresia can coexist with totally anomalous pulmonary venous connection, so can totally anomalous pulmonary venous connection coexist with the so-called "hypoplastic left heart complex". In most cases of totally anomalous pulmonary venous connection, the components of the left heart appear small as they are compressed by the hypertensive right ventricle, with the ventricular septum bowing severely to the left. In some patients with totally anomalous pulmonary venous connection, however, the left ventricle, aortic and mitral valves are truly structurally small. It is very possible that some of the patients dying after attempted surgical repair of totally anomalous pulmonary venous connection may also have exhibited the so-called "hypoplastic left heart complex". This phenotype is certainly an area that needs further study and elucidation.

Initially, the members of the coding committee of the Association for European Paediatric Cardiology, whilst endorsing and supporting retention of the term hypoplastic left heart syndrome for all the reasons discussed above, were reticent to create a separate code for the hypoplastic left heart complex within the European Paediatric Cardiac Code. The coding committee was not convinced that this relatively newly defined entity could be objectively distinguished on anatomical or physiological criterions as a distinct and separate lesion, and thus warrant an independent term. They preferred initially to list the various component parts of the complex with appropriate qualifiers, as will be shown below. This approach is in keeping with the overall underlying "atomic" structure to be found within the European Paediatric Cardiac Code, and the wish to avoid conglomerate terms. Part of the remit of the Nomenclature Working Group, however, is to be inclusive of all terms used by a substantial body of those in the field of paediatric cardiology and surgery, unless these terms are known to be scientifically incorrect. The Nomenclature Working Group, therefore, determined that the three terms "hypoplastic left heart syndrome without intrinsic valvar stenosis or atresia", "hypoplasia of the left heart without intrinsic valvar stenosis or atresia", and "hypoplastic left heart complex", should be used as synonyms and mapped between the two nomenclature systems, as will be detailed below.

In coding for hypoplastic left heart syndrome, the European Paediatric Cardiac Code has one code, specifically 01.01.09. Further description of the details of the lesion is achieved by selecting the specific codes related to every abnormal segment or structure, following the overall atomic approach, as will be discussed in more detail below. When using the system of coding established by the International Congenital Heart Surgery and Database Project, in contrast, the global term of "hypoplastic left heart syndrome" or "hypoplastic left heart syndromerelated malformation" is selected, followed by choice from the combination of lesions which best describes 
the problem at hand. This is the molecular approach, also to be discussed below.

The reader using the list of names in the International Paediatric and Congenital Cardiac Code derived from the earlier collaborations between the group established by the European Association for CardioThoracic Surgery and the Society of Thoracic Surgeons is advised that several anomalies, such as severely unbalanced atrioventricular septal defect, double outlet right ventricle with left ventricular hypoplasia, tricuspid atresia with transposition, double inlet left ventricle with transposition, and other functionally univentricular hearts with a dominant right ventricle, with or without obstruction of the aortic arch, are not considered under the umbrella of "hypoplastic left heart syndrome", but should be classified within the group of lesions termed "hypoplastic left heart syndrome-related malformation." For those using the version of the International Code derived from the original European Paediatric Cardiology Code, these lesions would be coded individually, without using the code 01.01.09 for "hypoplastic left heart syndrome", also as we discuss later in this review.

We should also re-emphasise that, previously, the International Congenital Heart Surgery Nomenclature and Database Project classified "aortic atresia with ventricular septal defect and a well-developed mitral valve and left ventricle" as a type of hypoplastic left heart syndrome. Even these rare cases with a ventricular septal defect show at least some degree of left or right ventricular hypoplasia. Measurements in autopsied specimens of the lengths of the ventricular inlets has revealed that the left ventricle is smaller than the right; even in cases with ventricular septal defect, the ratio between the ventricular lengths is always less than $1 .{ }^{36}$ This lesion, nonetheless, has since been reclassified as a "hypoplastic left heart syndrome-related malformation" because it does not include significant left ventricular hypoplasia, which is considered an essential element of hypoplastic left heart syndrome. Thus, hearts with "aortic atresia with ventricular septal defect and a well-developed mitral valve and left ventricle" are now classified in the version of the International Code derived from the International Congenital Heart Surgery Nomenclature and Database Project as a "hypoplastic left heart syndrome-related malformation", because they are not truly part of the hypoplastic left heart syndrome.

\section{Pathophysiology}

The variable pathophysiology of patients diagnosed with hypoplastic left heart syndrome becomes important because of the implications as to whether it is possible successfully to achieve biventricular as opposed to functionally univentricular repair. At the severe end of the spectrum of patients classified within the syndrome, the systemic circulation is completely dependent on the right ventricle and flow through the arterial duct, with flow in the aortic arch and the ascending aorta being retrograde. This pathophysiology is seen in the setting of aortic atresia with mitral atresia or stenosis. At the mild end of the spectrum, the systemic circulation may only be partially dependent on the right ventricle and flow through the arterial duct, as seen in some patients with aortic stenosis and mitral stenosis, those with aortic stenosis with left ventricular hypoplasia, or in those diagnosed with the hypoplastic left heart complex. In this setting, the flow to the descending aorta is dependent on the right ventricle and arterial duct, while flow to the ascending aorta and various portions of the aortic arch and branches are supplied by antegrade flow from the left ventricle. In a very few patients with the complex, the systemic circulation may be entirely dependent on the left ventricle in the presence of lesser degrees of obstruction within the left heart, although such patients are usually in severe congestive cardiac failure, and require surgical correction.

In the greater majority of patients with hypoplastic left heart syndrome, the only surgical reconstruction possible is the functionally univentricular approach using the Norwood, or Norwood-like, operation in the neonatal period, transferring the systemic circulation so that it exits directly from the right ventricle, followed eventually by a Fontan-type operation. Biventricular repair may be possible, however, for some patients at the milder end of the syndrome. The potential exists for left ventricular growth after birth ${ }^{23,25,28}$ and after biventricular repair. ${ }^{29}$ Accurate understanding of the pathophysiology in each patient is important, as it may help to determine whether biventricular repair should be considered.

\section{The atrial septum in hypoplastic left heart syndrome}

As our understanding of hypoplastic left heart syndrome has improved, it has become increasingly apparent that the morphology of the atrial septum at the time of birth will influence significantly the pathophysiology and haemodynamic state of the neonate. These variants of atrial septal morphology may be of particular importance during fetal development. ${ }^{37}$ Furthermore, some variants of atrial septal morphology can be fatal if untreated or improperly treated, and can be quite difficult to treat with balloon septostomy. 


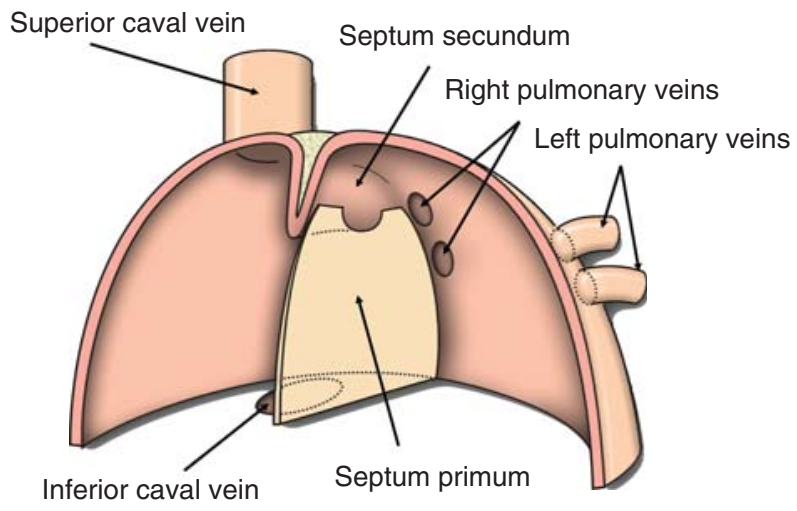

Figure 1.

The cartoon shows a coronal view of the atrial chambers, illustrating how the superior and inferior caval veins enter the right atrium, and the pulmonary veins enter the left atrium. The normal attachment of the flap valve of the atrial septum, the primary septum, or septum primum, is shown to the left atrial side of infolded superior rim of the oval foramen, usually called the septum secundum.

\section{The normal atrial septum}

The flap valve of the oval foramen, or the foramen ovale, representing the primary atrial septum, or septum primum, normally has an attachment of its half-moon-shaped superior margin to the left side of the infolded superior muscular rim of the foramen, called the secondary septum, or septum secundum. Dissection of any normal heart will demonstrate that this superior limbic band is the deep infolding between the attachments of the right pulmonary veins to the left atrium, and the caval veins to the right atrium (Fig. 1). In hypoplastic left heart syndrome, as in the normal newborn, the space between the half-moon-shaped superior margin of the flap valve and the superior rim of the oval foramen is usually patent. Postnatal bulging of the flap valve resulting from increased pulmonary venous return usually stretches the flap valve, with further opening of the oval foramen (Fig. 2).

\section{Defect within the oval fossa, or "ostium secundum" atrial septal defect}

The morphology of the atrial septum is similar to that described above, but a hole exists within the substance of the flap valve in addition to the oval foramen. Some investigators also include examples of a large, or "stretched", oval foramen in this category. If the defect is large, it may be difficult to limit flow of blood to the lungs prior to surgical intervention using the Norwood procedure or similar operations. It is important to distinguish this condition from leftward displacement of the flap valve, or septum primum, as described below.

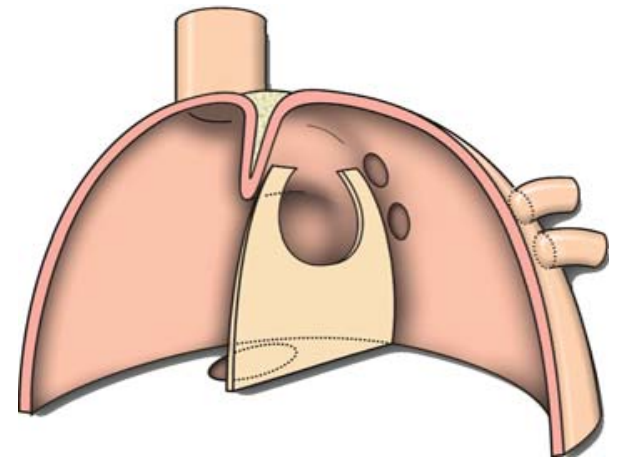

Figure 2 .

The cartoon demonstrates the stretched oval foramen (foramen ovale) with postnatal increased pulmonary venous return in the presence of normal attachment of the primary atrial septum (septum primum) to the infolded superior rim of the oval foramen, the septum secundum.

\section{Congenitally small or absent oval foramen, or premature closure of the oval foramen}

In this setting, the flap valve, or septum primum, and the infolded superior rim, or the septum secundum, are partially or totally adherent in newborns, when the oval foramen is expected to be patent. Typically, the flap valve is thickened and muscular compared with the thin, often translucent, appearance found in the normal heart of neonates at this age. In addition, the two faces of the atrial septum are often featureless, with the rims of the oval fossa and the half-moon shape of the superior margin of the flap valve not apparent. This type of atrial septum is more commonly seen in patients with patent mitral and aortic valves with aortic stenosis. While it has been thought by some that so-called premature closure of the oval foramen was a primary lesion causing hypoplasia of the left heart, it has also been postulated that the atrial septum becomes secondarily sealed because of left atrial hypertension from poor left ventricular compliance due to the aortic stenosis.

\section{Leftward displacement of flap valve, or septum primum}

In a large number of cases of hypoplastic left heart syndrome, most often those with mitral and aortic atresia, the superior aspect of the flap valve or "septum primum" is attached to the roof of the left atrium to the left, and posterior, relative to the infolded "septum secundum". Thus, there is a gap of at least 4 millimetres in the newborn between the superior rim and the flap valve. In some, however, the gap can be much larger, with the flap valve being attached as far left as the origin of the left atrial appendage. Sufficient lateral displacement can give the false impression of a large atrial septal defect, because the flap valve is not found in its expected location adjacent 


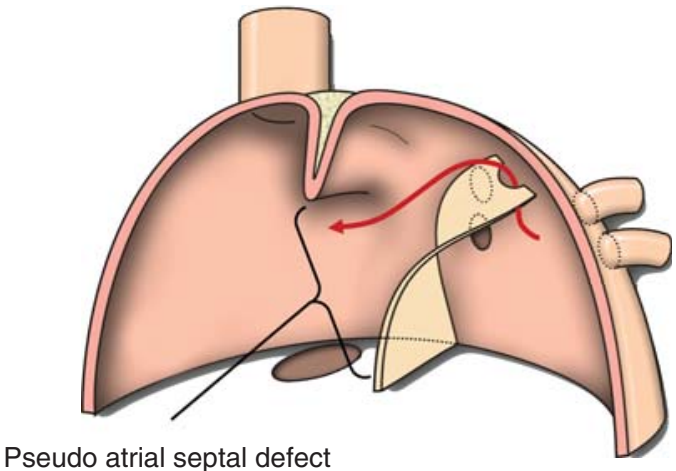

Figure 3.

This cartoon shows leftward displacement of the primary atrial septum, flap valve, or septum primum. The arrow passes through the oval foramen. Note the appearance of a large pseudo-defect beneath the persisting infolding marking the septum secundum.

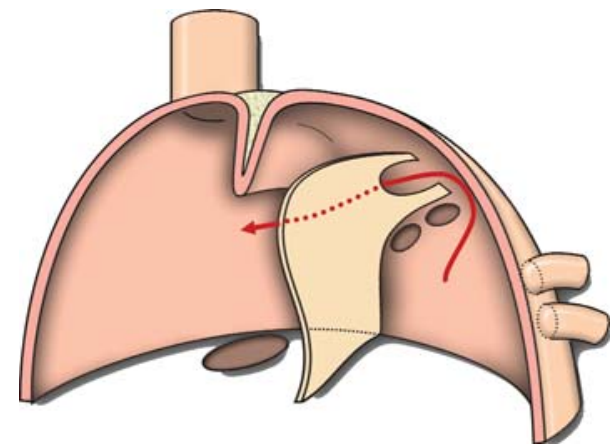

Figure 4.

This cartoon shows bulging of the displaced flap valve formed by the primary atrial septum, or septum primum, due to increased postnatal pulmonary venous return, with the oval foramen partially obstructed as it apposes the roof of left atrium. The arrow shows the pathway of flow from the left atrium.

to the superior margin or septum secundum (Fig. 3). Furthermore, in the most extreme cases of leftward displacement, postnatal rightward bulging of the flap valve may result in a restrictive oval foramen, as the flap valve is pushed up against the roof of the left atrium (Fig. 4). With the normal attachment of the flap valve to the superior rim, postnatal bulging usually results in stretching of the flap valve and further opening of the oval foramen, as discussed above (Fig. 2 ). The essence of the malformation is that the posterior aspect of the atrial septum is normally located, but the anterior aspect is laterally displaced. In this way, the flap valve forms a hood over the right pulmonary veins, which is sometimes responsible for the appearance of turbulence on Doppler echocardiography without other evidence of pulmonary venous obstruction.
Interatrial communication through the primary foramen or ostium primum

Many consider examples of unbalanced common atrioventricular septal defect, or common atrioventricular canal, with significant right ventricular dominance to be a form of hypoplastic left heart syndrome. In the version of the International Code derived from the International Congenital Heart Surgery Nomenclature and Database Project, this lesion is considered a type of "hypoplastic left heart syndrome-related malformation". While reconstruction of the aortic arch, and construction of systemic-to-pulmonary shunts, are similar to those procedures offered for other patients with the hypoplastic left heart syndrome, these patients with a right dominant atrioventricular septal defect commonly have a large interatrial communication through the primary foramen, and hence may not require atrial septectomy at the time of the Norwood operation. More importantly, like patients with large atrial septal defects in the oval fossa, they may be difficult to manage preoperatively because of the lack of any restriction of the flow of blood to the lungs.

\section{Therapeutic options for patients with the hypoplastic left heart syndrome}

Three surgical approaches have evolved over the years and are available today:

- multistage reconstructive surgery based on a single ventricle physiology, popularized by Norwood et al..$^{38}$

- cardiac replacement championed by Bailey and associates $^{39}$

- biventricular repair, as used for the patients at the mild end of the spectrum of hypoplastic left heart syndrome, ${ }^{29}$ as well as for the patients with aortic atresia with ventricular septal defect and a welldeveloped left ventricle, technically a "hypoplastic left heart syndrome-related malformation". 40,41

While the first two approaches can be applied to any patient with hypoplastic left heart syndrome, the biventricular approach can be used in very few patients, and requires an extremely careful process of evaluation and selection. Much of the debate over the last 15 years has been centered on the advantages and disadvantages of the Norwood operation as opposed to neonatal cardiac transplantation. Both approaches are based on entirely different surgical philosophies. Different centres tend to favour one or the other of these approaches, while some offer both, and leave the final decision to the parents. ${ }^{42}$ It is possible for a suitably mature programme to obtain excellent results by selectively offering staged palliation, transplantation, 
and in suitable cases, biventricular repair. ${ }^{43}$ Some centres, of course, continue to offer the fourth, nonsurgical, option of supportive care, called by some compassionate care, ${ }^{44}$ and by others passive euthanasia. ${ }^{45}$ Considerations of this last option raise a number of ethical issues, but these are beyond the scope of our present purpose, and will not be further discussed.

\section{Multistage reconstructive operations}

The first palliative operation for patients with hypoplastic left heart syndrome was reported in 1970, by Cayler and associates. ${ }^{46}$ It consisted of an anastomosis between the right pulmonary artery and the ascending aorta, along with bilateral banding of the pulmonary arteries. This patient remained alive at 3 years of age. ${ }^{47}$ An early attempt at surgical treatment, proposed by Norwood in 1977, involved construction of a modified Glenn shunt, a side-to-side anastomosis between the aorta and the pulmonary trunk, and banding of the left pulmonary artery. This patient died in the early postoperative period from severe acidosis and arterial desaturation. ${ }^{14}$ Doty et al. ${ }^{16,48}$ also attempted, in 6 neonates, to connect the partitioned right atrium to the pulmonary arteries by means of a conduit placed between the inferior and superior caval veins and the distal pulmonary artery, and to connect the proximal pulmonary trunk to the aorta with another conduit. All of their patients died of low cardiac output related to the elevated pulmonary vascular resistance in the neonatal period. These unfavorable early experiences clearly set the stage for the necessity of a multistaged approach.

The earliest first-stage operations suggested by Norwood and associates ${ }^{14}$ had some similarity to an operation performed by Litwin and associates ${ }^{49}$ for interruption of the aortic arch. This involved the placement of a non-valved conduit between the pulmonary trunk and the descending aorta, together with banding of the pulmonary trunk. Then, in 1980, Norwood and his associates ${ }^{14}$ proposed placement of a valved conduit between the right ventricular outflow tract and the descending aorta, together with banding of the pulmonary trunk. This approach was quickly abandoned in favour of a more direct technique, as reported in $1981 .{ }^{15}$ In this subsequent approach, the pulmonary trunk was transected proximal to its bifurcation, and was anastomosed directly to an incision in the ascending aorta and aortic arch, avoiding the use of any foreign material. The operation was completed by the construction of a central aortopulmonary shunt of 4 millimetres, and is considered to be the earliest "Norwood operation". Of the 16 patients in whom such first stage reconstruction was attempted, only a minority survived; furthermore, only one survived to undergo the Fontan operation at the age of 14 months and this patient died 2 days later of low cardiac output.

At around the same time, Doty and associates ${ }^{16}$ suggested placing a tubular graft between the proximal pulmonary trunk and the aortic arch, bringing a calibrated 3 millimetre opening in the graft into continuity with the distal pulmonary arteries to provide balance between the pulmonary and systemic flows of blood. The patient in whom the procedure was attempted died suddenly 12 weeks after the operation. Autopsy revealed that the calibrated opening in the graft had been narrowed considerably by neointimal growth, measuring only 1 millimetre at the time of death. In addition, the proposed technique failed to deal with the problem of the adequate flow of blood to the coronary arteries provided through the diminutive aorta. Recognizing these limitations, Doty ${ }^{15}$ stated that the technique proposed by Norwood and his associates was likely to be better in dealing with both these problems. It should also be remembered that, in 1979, Mohri and associates ${ }^{50}$ had described palliation for the hypoplastic left heart syndrome by interposing a conduit between the pulmonary trunk and the descending aorta, combined with ligation of the arterial duct, and banding of the pulmonary trunk distal to the insertion of the conduit.

In 1980, nonetheless, Norwood and associates ${ }^{14}$ established the principles of the first stage of their planned sequence of operations as follows:

- establishment of a permanent communication between the right ventricle and aorta;

- limitation of flow of blood to the lungs to attenuate the pulmonary vascular changes secondary to elevated pulmonary blood flow and pressure;

- insurance of a satisfactory interatrial communication.

These principles have remained remarkably constant over the last 25 years, and still apply today. More recently, assurance of the adequacy of the coronary arterial perfusion has become recognized as an essential fourth principle. Subsequently, at a second operation, physiologic correction is achieved by separating the systemic and the pulmonary circulations using a Fontan-type procedure. ${ }^{14}$ Over the last 10 to 15 years, it has become accepted to add an intermediate stage, in the form of a hemi-Fontan operation or construction of a bidirectional superior cavopulmonary, or Glenn, shunt, before performing the Fontan operation, increasing to three the number of operations in the multistaged reconstructive surgical approach. ${ }^{51,52}$ The first patient with hypoplastic left heart syndrome successfully to undergo and survive the Fontan-type operation was reported by Norwood et al. ${ }^{38}$ in 1983. This landmark publication finally offered hope for 
those born with this previously lethal cardiac malformation.

Since the early 1980s, there have also been several modifications to Norwood's initial operation, hoping to fulfill more reliably the surgical criterions for the first stage of palliation and to prepare the patient to become an optimal candidate for the Fontan operation. These modifications have included the following:

- use of homograft patch to reconstruct the aortic arch and the opened ascending aorta, and bring them over the divided proximal pulmonary trunk ${ }^{40,51}$

- use of complete tube from the proximal pulmonary trunk to the aortic arch ${ }^{40}$

- techniques of direct reconstruction of the aortic arch and ascending aorta without prosthetic material $^{15,53,54}$

- direct anastomosis between the proximal pulmonary trunk and the aortic arch, augmented distally with a small homograft patch.

There have also been different types of shunt used, such as a central shunt, a modified Blalock-Taussig shunt, a classical Blalock-Taussig shunt, ${ }^{55}$ and, rarely in an infant, a concomitant Glenn shunt. The sizes of the systemic-to-pulmonary arterial shunts have become smaller in recent years. Initially, it was standard to use a shunt of 4 millimeters, but more recently, those of 3.5 millimetres, and now even 3 millimetres, are being used.

The idea of placing a conduit from the right ventricle to the pulmonary arteries during the first stage of palliation dates back to the earlier work of Norwood, who used valved Hancock and non-valved polytetrafluoroethylene conduits. ${ }^{15,56,57}$ The fact that the conduits had diameters of 12 millimetres was probably the cause of the negative outcome for this initial experience, and the technique was abandoned for years. ${ }^{56}$ The Japanese surgeon Kishimoto described performing the Norwood operation with a conduit placed from the right ventricle to the pulmonary arteries in the pages of this journal in $1993,{ }^{58}$ and again later in 1999. ${ }^{59}$ Recently, a few reports, mostly from Japanese cardiac surgical centres, have revisited the use of conduits placed from the right ventricle to the pulmonary arteries, either a xenopericardial conduit containing a bicuspid valve 6 millimeters in diameter, ${ }^{59}$ or polytetrafluoroethylene tubes of 4,5 and 6 millimetres in diameter. ${ }^{60,61}$ Other centres have also reported favourable experiences ${ }^{56}$. Despite these earlier experiences, it is Sano who is usually credited for the spread in popularity of the use of the right ventricle to pulmonary artery conduit during the Norwood operation, and this technique is now frequently described in Europe and North America as the Sano modification. ${ }^{61,62}$
In earlier experiences, the Fontan operation was performed as the second stage, usually when the patient was aged around 18 to 24 months. ${ }^{51}$ As discussed above, since the early 1990s, it has now become customary to introduce an intermediate procedure as the second stage, before proceeding with the Fontan operation. ${ }^{40,51}$ The intermediate stage was proposed with the intent of decreasing at an earlier age the volume load on the systemic right ventricle, achieving this by replacing the systemic- to-pulmonary arterial shunt with a superior cavopulmonary shunt, the latter created either by means of a bidirectional superior cavopulmonary anastomosis ${ }^{40}$ or a hemiFontan procedure. ${ }^{51}$ These procedures are usually planned around 6 months of age, but have been successfully performed in patients as young as 1 month. ${ }^{55}$ Nowadays, therefore, the final stage is the third step of staged palliation, and is the completion of the Fontan operation, either by creating a lateral tunnel, ${ }^{51,55}$ or else constructing an extracardiac tunnel. ${ }^{63,64}$ The procedure may include fenestration of either the interatrial baffle ${ }^{55}$ or extracardiac tunnel, or the exclusion of one or more hepatic veins from the systemic venous pathway. ${ }^{51}$

Recently, interest has developed for a hybrid surgical and interventional approach to initial palliation. This feat is achieved by using catheterization to place a stent to maintain ductal patency, along with surgical or transcatheter placement of bilateral bands on the pulmonary arteries. Using this initial strategy, it is feasible to achieve the Fontan circulation with only one surgical procedure, namely a hemi-Fontan operation with concomitant reconstruction of the aortic arch, with completion of the Fontan procedure again being achieved using a transcatheter approach. ${ }^{65-69}$

\section{Cardiac replacement}

The pioneering work of Bailey and his associates 39,70 has resulted in the establishment of neonatal and infant cardiac transplantation as a viable alternative to multistage reconstructive procedures. The main advantage of cardiac transplantation is the replacement, in one operation, of a functionally univentricular heart in which the right ventricle is fulfilling a systemic role with a normal heart possessing four chambers and with normal physiology. Although initial survival following transplantation has been excellent, the approach has been seriously limited by the grossly inadequate availability of donor hearts. Furthermore, this approach requires lifelong immunosuppression, with the attendant risks of rejection, infection, graft atherosclerosis, and malignancies. The challenge of selecting which patients are best treated by cardiac replacement is beyond the scope of our present purpose, and will not be further discussed. 


\section{Biventricular repair}

Recently, there has been increased interest in biventricular repair for some patients at the milder end of the syndrome. Thus, Tchervenkov and associates ${ }^{29}$ have identified a group of patients who had hypoplasia of the structures of the left ventricle and aorta without intrinsic valvar stenosis or atresia, called by them the hypoplastic left heart complex. Most of these patients have successfully undergone primary biventricular repair, consisting of extensive enlargement of the aortic arch and ascending aorta with a pulmonary homograft and closure of the interventricular and interatrial communications, but using a conservative approach for the obstructive lesions in the left ventricular outflow tract. ${ }^{29}$

Another group of patients successfully undergoing primary biventricular repair are those with aortic atresia with ventricular septal defect and a well-developed left ventricle. ${ }^{40,41}$ Successful repair of this combination of lesions was initially reported in 1981 by Norwood and Stellin. ${ }^{71}$ In 1987, Yasui et al. described a different repair $^{72}$ consisting of establishing continuity between the proximal pulmonary trunk and the aorta, patching the ventricular septal defect so that left ventricular blood was directed through the pulmonary valve, and placing a conduit from the right ventricle to the pulmonary arteries, a procedure referred to as both the Yasui operation and the Norwood/Rastelli operation. Yet another technique ${ }^{41}$ involves patching the ventricular septal defect to the pulmonary trunk, which after its division, and before its bifurcation, is connected with a tube graft to the aortic arch, distal ascending aorta, and the proximal descending aorta. The right ventricle is then connected with a valved homograft to the distal pulmonary arteries, thus achieving a biventricular repair.

A third group of patients who may be candidates for a biventricular repair are those with critical aortic stenosis and left ventricle hypoplasia who fulfill the criterions established by Rhodes et al. for left ventricular size, ${ }^{34}$ or the criterions established by the Congenital Heart Surgeons Society for biventricular repair. ${ }^{35}$

\section{Nomenclature and crossmap for diagnoses and procedures related to hypoplastic left heart syndrome}

Thus far, we have summarized the historical aspects of terminology, and the development of surgical treatment for hypoplastic left heart syndrome. Although we have suggested a common definition for hypoplastic left heart syndrome, the term does not provide the details necessary to describe in full the patients afflicted with the syndrome. Since Noonan and Nadas first coined the term in 1958, there have been dramatic developments in invasive and non-invasive imaging that now allow for precise diagnoses. Moreover, since the early 1980s, the development of surgical procedures has offered the prospect of survival from these once-lethal anomalies. Hence, a more detailed, comprehensive, and universal scheme of classification is required for description of cases, and collection of data, in the 21 st century.

In 2000, two extensive nomenclatures were published almost simultaneously. These were the European Paediatric Cardiac Code, prepared on behalf of the Association for European Paediatric Cardiology ${ }^{73,74}$ and the International Congenital Heart Surgery Nomenclature and Database Project, undertaken at the behest of the European Association for Cardio-Thoracic Surgery and the Society of Thoracic Surgeons. ${ }^{75}$ Both reflected the need for a more detailed description of anomalies, such as those included in the term hypoplastic left heart syndrome, but the resulting solutions differed significantly. The European Paediatric Cardiac Code lists all individual malformations in a segmental and sequential fashion. The surgical tree for nomenclature, in contrast, is presented as a listing of both individual lesions and formalized groupings, representing lesions that may be found together. The surgical list may also be accessed in a segmental and sequential fashion. The structural difference between the two systems is analogous to the difference between atoms and molecules. The European Paediatric Cardiac Code utilizes an atomic approach, using mostly basic diagnostic terminology, but not formally grouping together the terms. Thus, in the European Paediatric Cardiac Code, under the heading "left ventricular anomalies", there exists an entry for hypoplastic left heart syndrome. The various details, or "atoms", of the associated anomalies of the left heart are coded separately within the lists available for the appropriate cardiac segment. The International Congenital Heart Surgery Nomenclature and Database Project, in contrast, uses a molecular approach, with formalized groupings of terms to represent the various lesions that may be found together. The latter nomenclature, therefore, contains an entire section entitled "hypoplastic left heart syndrome". The version of the International Code derived from the International Congenital Heart Surgery Nomenclature and Database Project, therefore, offers a listing of the various possible combinations of hypoplasia, stenosis, and atresia within the left heart and aorta. The advantage of the molecular approach is that a single selection may be made to code a group of several lesions found together. The disadvantage of the molecular approach is that the list of names is longer, and potentially more challenging to navigate without computerized 
navigational assistance. Both approaches, nonetheless, be they atomic or molecular, will allow proper coding of the diagnoses and procedures of congenital cardiac disease.

Faced with two complete but different lists of names, the Nomenclature Working Group was formed in 2001 with the remit to cross-map the existing systems, and hence create the International Paediatric and Congenital Cardiac Code. ${ }^{2-7}$ In the subsequent pages, we present the work of the group in crossmapping the names for the parts making up the hypoplastic left heart syndrome.

\section{Nomenclature crossmap for diagnoses related to hypoplastic left heart syndrome}

In Table 1, we show the names for diagnoses related to hypoplastic left heart syndrome from the version of the International Code derived from the nomenclature of the International Congenital Heart Surgery Nomenclature and Database Project of the Society of Thoracic Surgeons and the European Association of Cardio-Thoracic Surgery. In Table 2, we show the equivalent and crossmapped terms from the version of the International Code derived from the nomenclature of the European Paediatric Cardiac Code of the Association for European Paediatric Cardiology.

As we have discussed previously, the approach utilized by the Association for European Paediatric Cardiology necessitates that combinations of individual codes are used to describe the possible variants of hypoplastic left heart syndrome. There was initially no separate code for the hypoplastic left heart complex in the European Pediatric Cardiac Code, but a simile has now been created, despite this remaining a somewhat controversial term. For the most part, the version of the International Code derived from the European Paediatric Cardiac Code lists the various diagnostic parts with appropriate qualifiers, as shown in Table 2.

In Table 1 , after giving the list of diagnostic terms for the classification of hypoplastic left heart syndrome, we also provide a listing of the diagnostic terms for the so-called "Hypoplastic left heart syndrome (HLHS)-related malformation", and finally a listing of a group of terms called the "Hypoplastic left heart syndrome (HLHS)-modifier". The latter is a list of terms that may be used to modify the different types of hypoplastic left heart syndrome and hypoplastic left heart syndrome-related malformations.

In the version of the International Code derived from the initial efforts of the Association for European Paediatric Cardiology (Table 2), there is no separation or grouping of the so-called "Hypoplastic left heart syndrome (HLHS)-related malformation". The individual conditions are listed as mutually exclusive diagnoses purely on their own merit.
The structure of the version of the International Code derived from the European Paediatric Cardiac Code also differs from the other version in the use of terms as modifiers or qualifiers. The version of the International Code derived from the International Congenital Heart Surgery Nomenclature and Database Project uses the concept of modifiers to list any additional diagnosis, which may be linked to their parent diagnosis. This surgical version of the International Code explicitly lists these modifiers with a formal linkage with the parent diagnosis, incorporating both diagnoses into the same multidiagnostic chain, as illustrated in Table 1. In contrast, although the version derived from the European Paediatric Cardiac Code has all of these diagnoses listed in its system, it does not explicitly link them to the primary diagnosis. The user is encouraged by linkages in the underlying structure of the hierarchy to go to the section dealing with, for example, coronary arterial anomalies, and then list the additional pathology present as part of the total diagnostic description. For the most part, each diagnosis is mutually exclusive, and stands alone. There are a few exceptions, where such linkages have become embedded in the accepted nomenclature of paediatric cardiologists, such as "pulmonary atresia with ventricular septal defect, including the Fallot type". ${ }^{6}$ Qualifiers, or terms with numerical codes beginning with a "Q" (Qx.xx.xx), exclusively give additional fine detail to a single or multiple diagnoses. As with the modifiers, more than one qualifier can be attached to such an individual term. ${ }^{74}$ These qualifiers cannot, in any part, be used on their own as individual terms. They are divided broadly into those adding diagnostic information, such as which leaflet of the tricuspid valve is involved in an abnormality, or the severity of aortic regurgitation; and those adding surgical information, such as the size of an interposition shunt, conduit, or device.

\section{Modifiers to describe the atrial septum in bypoplastic left heart syndrome}

The significant incidence of varying anomalies of the atrial septum has necessitated creating appropriate names to describe the variants. In an anatomical series of 102 cases of the hypoplastic left heart syndrome, the atrial septum was intact in 11 hearts. ${ }^{36}$ In the same series of hearts, three-tenths of the specimens showed malalignment of the primary septum, as described by Weinberg et al. ${ }^{37}$ This particular anatomical finding was, however, much more frequent in hearts with absent left atrioventricular connection, being found in half the cases, as opposed to only onequarter of those with concordant atrioventricular connections. ${ }^{36}$ 
Table 1. The European Association for Cardiothoracic Surgery - Society of Thoracic Surgeons derived version of the International Paediatric and Congenital Cardiac Code for Diagnoses related to Hypoplastic Left Heart Syndrome.

Hypoplastic left heart syndrome (HLHS)

Hypoplastic left heart syndrome (HLHS), Aortic atresia + Mitral atresia

Hypoplastic left heart syndrome (HLHS), Aortic atresia + Mitral stenosis

Hypoplastic left heart syndrome (HLHS), Aortic atresia + Mitral stenosis, IVS

Hypoplastic left heart syndrome (HLHS), Aortic atresia + Mitral stenosis, VSD

Hypoplastic left heart syndrome (HLHS), Aortic atresia + Mitral stenosis, VSD, Nonrestrictive VSD

Hypoplastic left heart syndrome (HLHS), Aortic atresia + Mitral stenosis, VSD, Restrictive VSD

Hypoplastic left heart syndrome (HLHS), Aortic stenosis + Mitral atresia

Hypoplastic left heart syndrome (HLHS), Aortic stenosis + Mitral atresia, Nonrestrictive VSD

Hypoplastic left heart syndrome (HLHS), Aortic stenosis + Mitral atresia, Restrictive VSD

Hypoplastic left heart syndrome (HLHS), Aortic stenosis + Mitral stenosis

Hypoplastic left heart syndrome (HLHS), Aortic stenosis + Mitral stenosis, IVS

Hypoplastic left heart syndrome (HLHS), Aortic stenosis + Mitral stenosis, VSD

Hypoplastic left heart syndrome (HLHS), Aortic stenosis + Mitral stenosis, VSD, Nonrestrictive VSD

Hypoplastic left heart syndrome (HLHS), Aortic stenosis + Mitral stenosis, VSD, Restrictive VSD

Hypoplastic left heart syndrome (HLHS), Aortic stenosis + MV hypoplasia

Hypoplastic left heart syndrome (HLHS), Aortic stenosis + MV hypoplasia, IVS

Hypoplastic left heart syndrome (HLHS), Aortic stenosis + MV hypoplasia, VSD

Hypoplastic left heart syndrome (HLHS), Aortic stenosis + MV hypoplasia, VSD, Nonrestrictive VSD

Hypoplastic left heart syndrome (HLHS), Aortic stenosis + MV hypoplasia, VSD, Restrictive VSD

Hypoplastic left heart syndrome (HLHS), Without intrinsic valvar stenosis or atresia (Hypoplastic aortic valve + mitral valve + left ventricle) (Hypoplastic left heart complex = HLHC)

Hypoplastic left heart syndrome (HLHS), Without intrinsic valvar stenosis or atresia (Hypoplastic aortic valve + mitral valve + left ventricle) (Hypoplastic left heart complex $=$ HLHC), IVS

Hypoplastic left heart syndrome (HLHS), Without intrinsic valvar stenosis or atresia (Hypoplastic aortic valve + mitral valve + left ventricle) (Hypoplastic left heart complex = HLHC), VSD

Hypoplastic left heart syndrome (HLHS), Without intrinsic valvar stenosis or atresia (Hypoplastic aortic valve + mitral valve + left ventricle) (Hypoplastic left heart complex = HLHC), VSD, Nonrestrictive VSD

Hypoplastic left heart syndrome (HLHS), Without intrinsic valvar stenosis or atresia (Hypoplastic aortic valve + mitral valve + left ventricle) (Hypoplastic left heart complex = HLHC), VSD, Restrictive VSD

Hypoplastic left heart syndrome (HLHS)-related malformation

Hypoplastic left heart syndrome (HLHS)-related malformation, Aortic atresia + VSD (well-developed MV and LV)

Hypoplastic left heart syndrome (HLHS)-related malformation, Aortic atresia + VSD (well-developed MV and LV), Nonrestrictive VSD

Hypoplastic left heart syndrome (HLHS)-related malformation, Aortic atresia + VSD (well-developed MV and LV), Restrictive VSD

Hypoplastic left heart syndrome (HLHS)-related malformation, DILV with transposition (DILV with ventricular-arterial discordance)

Hypoplastic left heart syndrome (HLHS)-related malformation, Double-outlet right ventricle with LV hypoplasia

Hypoplastic left heart syndrome (HLHS)-related malformation, Interrupted aortic arch with severe subaortic stenosis

Hypoplastic left heart syndrome (HLHS)-related malformation, Severely unbalanced AV septal defect (AVSD) (AVC)

Hypoplastic left heart syndrome (HLHS)-related malformation, Straddling mitral valve with LV hypoplasia

Hypoplastic left heart syndrome (HLHS)-related malformation, Tricuspid atresia with transposition (Tricuspid atresia with ventricular-arterial discordance)

Hypoplastic left heart syndrome (HLHS)-related malformation, Univentricular hearts with RV morphology

Hypoplastic left heart syndrome (HLHS)-related malformation, Univentricular hearts with RV morphology, With aortic arch obstruction

Hypoplastic left heart syndrome (HLHS)-related malformation, Univentricular hearts with RV morphology, Without aortic arch obstruction

\subsection{1 .09}

$01.01 .09,09.15 .03,06.02 .01$

$01.01 .09,09.15 .03,06.02 .92$

$01.01 .09,09.15 .03,06.02 .92,07.21 .00$

01.01.09, 09.15.03, 06.02.92, 07.10.00

$01.01 .09,09.15 .03,06.02 .92,07.14 .04$

$01.01 .09,09.15 .03,06.02 .92,07.14 .01$

$01.01 .09,09.15 .92,06.02 .01$

$01.01 .09,09.15 .92,06.02 .01,07.14 .0$

$01.01 .09,09.15 .92,06.02 .01,07.14 .0$

$01.01 .09,09.15 .92,06.02 .92$

$01.01 .09,09.15 .92,06.02 .92,07.21 .00$

$01.01 .09,09.15 .92,06.02 .92,07.10 .00$

$01.01 .09,09.15 .92,06.02 .92,07.14 .04$

$01.01 .09,09.15 .92,06.02 .92,07.14 .0$

$01.01 .09,09.15 .92,06.02 .04$

$01.01 .09,09.15 .92,06.02 .04,07.21 .00$

01.01.09, 09.15.92, 06.02.04, 07.10.00

$01.01 .09,09.15 .92,06.02 .04,07.14 .04$

$01.01 .09,09.15 .92,06.02 .04,07.14 .01$

07.06.17

07.06.17, 07.21.00

07.06.17, 07.10.00

$07.06 .17,07.14 .04$

$07.06 .17,07.14 .01$

$09.15 .03,07.10 .00$

$09.15 .03,07.10 .00,07.14 .04$

$09.15 .03,07.10 .00,07.14 .01$

$01.04 .04,01.05 .01$

01.01.04, 07.07.00

$09.29 .31,07.09 .00+\mathrm{Q} 1.40 .05$

06.07.26+Q1.40.05

06.02.09, 07.07.00

$06.01 .01,01.05 .01$

07.08 .42

$07.08 .42,09.28 .20$

$07.08 .42,09.28 .20+$ Q1.90.69 
Hypoplastic left heart syndrome (HLHS)-modifier, Anomalous pulmonary venous connection

Hypoplastic left heart syndrome (HLHS)-modifier, Anomalous pulmonary venous connection, Partial

04.08 .07

Hypoplastic left hear

04.07 .01

Hypoplastic left heart syndrome (HLHS)-modifier, Aortic arch discrete coarctation

Hypoplastic left heart syndrome (HLHS)-modifier, Aortic arch hypoplasia

09.29 .01

Hypoplastic left heart syndrome (HLHS)-modifier, Aortic arch interrupted

09.29 .11

Hypoplastic left heart syndrome (HLHS)-modifier, Aortic arch normal

Hypoplastic left heart syndrome (HLHS)-modifier, Atrial septum intact

Hypoplastic left heart syndrome (HLHS)-modifier, Atrial septum with ASD

09.29 .31

09.28 .21

Hypoplastic left heart syndrome (HLHS)-modifier, Atrial septum with ASD, ASD nonrestrictive

05.03 .10

05.04 .01

Hypoplastic left heart syndrome (HLHS)-modifier, Atrial septum with ASD, ASD restrictive

Hypoplastic left heart syndrome (HLHS)-modifier, Atrial septum with ASD, Posterior displacement of septum primum (malattachment of

05.04 .08

05.04 .09

atrial septum)

Hypoplastic left heart syndrome (HLHS)-modifier, Coronary artery anomaly

Hypoplastic left heart syndrome (HLHS)-modifier, Coronary artery anomaly, Anomalous origin or takeoff

05.04 .10

Hypoplastic left heart syndrome (HLHS)-modifier, Levoatrial-cardinal vein (Persistent left posterior cardinal vein) (LA to innominate vein)

Hypoplastic left heart syndrome (HLHS)-modifier, Pulmonary venous stenosis

Hypoplastic left heart syndrome (HLHS)-modifier, RV PDA dependent systemic circulation - Not present

Hypoplastic left heart syndrome (HLHS)-modifier, RV PDA dependent systemic circulation - Partial

Hypoplastic left heart syndrome (HLHS)-modifier, RV PDA dependent systemic circulation - Total

Hypoplastic left heart syndrome (HLHS)-modifier-Coronary artery fistula(s) or sinusoid(s), (Coronary-cameral fistula(s)) absent

Hypoplastic left heart syndrome (HLHS)-modifier-Coronary artery fistula(s) or sinusoid(s), (Coronary-cameral fistula(s)) present

Hypoplastic left heart syndrome (HLHS)-modifier-Coronary artery fistula(s) or sinusoid(s), (Coronary-cameral fistula(s)) present, Coronary artery not connected to aorta

Hypoplastic left heart syndrome (HLHS)-modifier-Coronary artery fistula(s) or sinusoid(s), (Coronary-cameral fistula(s)) present, Coronary artery obstructed completely

Hypoplastic left heart syndrome (HLHS)-modifier-Coronary artery fistula(s) or sinusoid(s), (Coronary-cameral fistula(s)) present, Coronary artery stenotic

Hypoplastic left heart syndrome (HLHS)-modifier-Coronary artery fistula(s) or sinusoid(s), (Coronary-cameral fistula(s)) present, Coronary artery unobstructed

Hypoplastic left heart syndrome (HLHS)-modifier-Coronary artery fistula(s) or sinusoid(s), (Coronary-cameral fistula(s)) present-Involved coronary $=\mathrm{Cx}$

Hypoplastic left heart syndrome (HLHS)-modifier-Coronary artery fistula(s) or sinusoid(s), (Coronary-cameral fistula(s)) present-Involved coronary $=$ LAD

Hypoplastic left heart syndrome (HLHS)-modifier-Coronary artery fistula(s) or sinusoid(s), (Coronary-cameral fistula(s)) present-Involved coronary $=\mathrm{RCA}$

$*=$ This term does not have a code because it is a section header in the nomenclature list and not a precise anatomic entity

ASD, atrial septal defect; AV, atrioventricular; AVC, atrioventricular canal; Cx, circumflex coronary artery; DILV, double inlet left ventricle; IVS, intact ventricular septum; LAD, left anterior descending coronary artery; LV, left ventricle/ventricular; MV, mitral valve; PDA, patent ductus arteriosus; RCA, right coronary artery; RV, right ventricular; VSD, ventricular septal defect 
Table 2. The Association for European Paediatric Cardiology derived version of the International Paediatric and Congenital Cardiac Code for the Diagnoses related to Hypoplastic Left Heart Syndrome.

Hypoplastic left heart syndrome,

Hypoplasia of the left heart without intrinsic valvar stenosis or atresia,

01.01 .09

may have a combination of the following terms added to it:

Aortic atresia,

07.06 .17

Aortic stenosis,

Aortic valvar "annulus" hypoplasia,

Mitral atresia,

Mitral stenosis,

Mitral valve annulus hypoplasia,

Left ventricular hypoplasia,

Each of these may have further qualifier codes added (see discussion in text of manuscript) for severity of stenosis or respective z-scores for valve hypoplasia.

Left ventricular hypoplasia can be further described by the following terms:

Left ventricular hypoplasia - diffuse,

Left ventricular hypoplasia of outflow tract,

Left ventricular hypoplasia of inflow tract,

Left ventricular hypoplasia of outflow tract and trabecular area,

09.15 .03

09.15 .92

09.15 .17

06.02 .01

06.02 .92

06.02 .04

07.07 .00

The status of the ventricular septum can then be additionally described:

Intact ventricular septum,

VSD,

Non-restrictive VSD,

Restrictive VSD,

The user may construct the lesions termed hypoplastic left heart syndrome related malformations in Table 1 using a combination of the previously listed and

below listed terms with numerical codes:

Double inlet right ventricle,

Double inlet left ventricle,

Tricuspid atresia,

Double outlet right ventricle,

Discordant VA connections (TGA),

AVSD with ventricular imbalance, - severe,

Subaortic stenosis, - severe,

Interrupted aortic arch

Ventricular imbalance: dominant right ventricle + hypoplastic left ventricle,

Straddling mitral valve,

Aortic arch obstruction

Aortic arch obstruction, - ruled out

07.07 .01

07.07 .02

07.07 .03

07.07 .04

07.21 .00

07.10 .00

07.14 .04

07.14 .01

The majority of hypoplastic left heart syndrome modifiers are accounted for by separate diagnoses, which can then be linked to hypoplastic left heart syndrome as

the user requires, with a few coronary arterial qualifiers added for finer detail:

Anomalous pulmonary venous connection,

Partially anomalous pulmonary venous connection(s)

Totally anomalous pulmonary venous connection,

Aortic arch normal,

01.04 .03

01.04 .04

06.01 .01

01.01 .04

01.05 .01

06.07.26 + Q1.40.05

$07.09 .00+\mathrm{Q} 1.40 .05$

09.29 .31

07.08 .42

06.02 .09

09.28 .20

$09.28 .20+\mathrm{Q} 1.90 .57$

Aortic coarctation,

04.08.07

04.07 .01

04.08 .05

09.28 .21

09.29 .01 
Table 2. The Association for European Paediatric Cardiology derived version of the International Paediatric and Congenital Cardiac Code for the Diagnoses related to Hypoplastic Left Heart Syndrome (Continued)
Aortic arch hypoplasia (tubular)

Interrupted aortic arch,

Intact atrial septum (no interatrial communication),

Interatrial communication ("ASD”),

Interatrial communication (“ASD”): non-restrictive,

Restrictive interatrial communication ("ASD”) with obligatory shunt,

Atrial septum malattachment: superior aspect of septum primum to left \& posterior (hypoplastic left heart type)

Coronary arterial abnormality,

Coronary artery: anomalous aortic origin/course,

Coronary fistula(s)/ sinusoids,

Coronary fistula(s)/ sinusoids not apparent,

Coronary fistula(s)/ sinusoids, - coronary artery without connection to aorta,

Coronary fistula(s)/ sinusoids, - coronary artery complete obstruction,

Coronary fistula(s)/ sinusoids, - coronary artery stricture,

Coronary fistula(s)/ sinusoids, - unobstructed coronary artery,

Coronary fistula(s)/ sinusoids, $-\mathrm{LCx}$

Coronary fistula(s)/ sinusoids, - LAD,

Coronary fistula(s)/ sinusoids, - RCA,

Endocardial fibroelastosis,

Persistent left posterior (laevo-atrial) cardinal vein (left atrium to innominate vein),

Pulmonary vein stenosis,

Arterial duct dependent systemic circulation, - not apparent,

Arterial duct dependent systemic circulation, - partial-incomplete,

Arterial duct dependent systemic circulation, - complete,

Abbreviations as for Table 1 and LCx, left circumflex coronary artery; TGA, transposition of the great arteries

09.29 .11

09.29 .31

05.03 .10

05.04 .01

05.04 .08

05.03 .05

05.04 .10

09.46 .00

09.42 .00

09.45 .00

09.45 .15

$09.45 .00+\mathrm{Q} 1.46 .05$

$09.45 .00+\mathrm{Q} 1.46 .04$

$09.45 .00+\mathrm{Q} 1.46 .02$

$09.45 .00+\mathrm{Q} 1.46 .01$

$09.45 .00+\mathrm{Q} 1.45 .53$

$09.45 .00+\mathrm{Q} 1.45 .52$

$09.45 .00+\mathrm{Q} 1.45 .54$

10.10 .12

04.01 .06

04.08 .91

09.27.08 + Q1.90.69

$09.27 .08+\mathrm{Q} 1.90 .70$

$09.27 .08+\mathrm{Q} 1.90 .71$ 
In order to describe properly the atrial septal morphology at birth, therefore, the following modifiers have been added to the names provided for description of the hypoplastic left heart syndrome in the version of the International Code derived from the International Congenital Heart Surgery Nomenclature and Database Project.

Hypoplastic left heart syndrome (HLHS)-modifier, Atrial septum intact

Hypoplastic left heart syndrome (HLHS)-modifier, Atrial septum with ASD

Hypoplastic left heart syndrome (HLHS)-modifier, Atrial septum with ASD, ASD nonrestrictive

Hypoplastic left heart syndrome (HLHS)-modifier, Atrial septum with ASD, ASD restrictive

Hypoplastic left heart syndrome (HLHS)-modifier, Atrial septum with ASD, Posterior displacement of septum primum (malattachment of atrial septum)

In the version of the International Code derived from the European Paediatric Cardiac Code, a combination of two terms with numerical codes is equivalent to these modifiers. This is in line with the differing structure of the two nomenclature systems as described above. Thus:

Hypoplastic left heart syndrome,

01.01 .09

may have one of the following terms added to it: Intact atrial septum (no interatrial communication), Interatrial communication ("ASD"),

Interatrial communication ("ASD"): non-restrictive, Restrictive interatrial communication ('ASD') with

05.03 .10 05.04 .01 05.04 .08 05.03 .05 obligatory shunt,

Atrial septum malattachment: superior aspect of septum primum to left \& posterior (hypoplastic left

05.04 .10 heart type),

A specifically malformed heart within the spectrum of hypoplastic left heart syndrome, therefore, would be coded as a combination of terms in the version of the International Code derived from the European Paediatric Cardiac Code, but these can now be directly mapped from the more complex terms contained in the version of the International Code derived from the International Congenital Heart Surgery Nomenclature and Database Project. For example:

Hypoplastic left heart syndrome (HLHS), Aortic atresia + mitral stenosis,

Hypoplastic left heart syndrome (HLHS) modifier, Anomalous pulmonary venous connection, Partial

Hypoplastic left heart syndrome (HLHS) modifier, Atrial septum with ASD, ASD restrictive

maps to the European Paediatric Cardiac Codes:

Hypoplastic left heart syndrome,

Partially anomalous pulmonary venous connection(s), 06.02 .92 Restrictive interatrial communication ("ASD") with 04.07 .01 obligatory shunt,

\section{Nomenclature for therapeutic options for hypoplastic left heart syndrome}

The nomenclature for therapeutic options must cover the following procedures:

- Norwood operation

- Transplantation

- Biventricular repair without prior Norwood operation

- Biventricular repair after the Norwood operation

- Transcatheter palliation

\section{Definition of the therapeutic options}

The following definitions and comments further describe these major options:

Norwood Operation In April 2000, The International Congenital Heart Surgery Nomenclature and Database Project defined this operation as "an aortopulmonary connection and neoaortic arch reconstruction resulting in univentricular physiology and pulmonary blood flow controlled with a calibrated systemic-topulmonary artery shunt". ${ }^{1}$

This definition has now been updated and we therefore offer the following definition of the Norwood operation:

"The Norwood operation is synonymous with the term 'Norwood (Stage 1)' and is defined as an aortopulmonary connection and neoaortic arch construction resulting in univentricular physiology and pulmonary blood flow controlled with a calibrated systemic-to-pulmonary artery shunt, or a right ventricle to pulmonary artery conduit, or rarely, a cavopulmonary connection".

This modification is so as to include alternative sources of flow of blood to the lungs besides simply a systemic-to-pulmonary arterial shunt. Furthermore, the term "reconstruction" was replaced in the definition by the term "construction", because the operation involves the construction of the neoaortic arch, not the reconstruction of the neoaortic arch.

In the version of the International Code derived form the International Congenital Heart Surgery Nomenclature and Database Project, the Norwood operation is named "Norwood (Stage 1)", with the parenthesis around "Stage 1" designed to recognize that the terms "Norwood" and "Stage 1" may be used a synonyms. In fact, although most centers call this operation the "Norwood operation", some centers refer to this operation as the "Stage 1 operation". In the version of the International Code derived for the European Paediatric Cardiac Code, the Norwood operation is named "Norwood type procedure".

The Nomenclature Working Group decided not to utilize the following terminology:

Norwood stage 1, Classic Norwood

Norwood stage 1, Modified Norwood 
In April 2000, the International Congenital Heart Surgery Nomenclature and Database Project defined these terms as follows:

Classic Norwood operation An operation characterized by an aortopulmonary connection with a neoaortic reconstruction using homograft material without aortic transection. Pulmonary arterial blood flow is by a calibrated systemic-to-pulmonary artery shunt.

Modified Norwood operation "Any number of operations which may include: aortic transection, aortopulmonary connection and neoaortic arch reconstruction without homograft material, or a combination of these techniques. Other modifications can include different methods of establishing calibrated systemic-topulmonary artery shunts and different methods of neoaortic arch reconstruction."

The International Congenital Heart Surgery Nomenclature and Database Project had stated that most surgeons working in the era from 1998 through 2000 considered the "classic" operation to include an aortopulmonary connection without aortic transection, and with neoaortic reconstruction using homograft material. The Nomenclature Working Group observed that this definition is neither clear nor universal in light of the fact that the earlier versions of the first stage did not involve augmentation with a patch as part of the aortic augmentation. Consequently, the International Code does not now include the terms "Classic Norwood" and "Modified Norwood" because they lack meaning and precision. Instead, the Nomenclature Working Group has created a coding system where the Norwood operation is described initially by documenting the technique of neoaortic construction. Next, additional modifiers are utilized to document the method used to enlarge the interatrial communication, or atrial septectomy, whether or not the isthmus was excised, further description of the reconstructive technique used for the native ascending aorta, the source of flow of blood to the lungs, and the strategy for cardiopulmonary bypass. The nomenclature module for hypoplastic left heart syndrome describes in detail the modification of conduits placed from the right ventricle to the pulmonary arteries. Systemic-to-pulmonary arterial shunts, in contrast, are not covered in such detail in this module because their size, type, anatomic origin, and anatomic insertion will be coded in a separate module of the database describing specifically the systemic-to-pulmonary arterial shunt employed.

Orthotopic cardiac transplantation Cardiac transplantation may be performed for hypoplastic left heart syndrome with or without reconstruction of the aortic arch, depending on the state of the aortic arch and degree of coarctation.

Biventricular repair The three groups of patients that may be considered for biventricular repair include those with the hypoplastic left heart complex, those with critical aortic stenosis with left ventricular hypoplasia, and those having aortic atresia with a ventricular septal defect. Biventricular repair may require simultaneous and/or remote repair of mitral stenosis at supravalvar, valvar, or subvalvar levels, subaortic stenosis, aortic stenosis, hypoplasia of the aortic arch, coarctation, or interruption of the aortic arch. This therapeutic option is predicated on the assumption that the small left ventricle is large enough to support the systemic circulation acutely, and has the potential for growth.

Biventricular repair after an initial first stage palliation A small subset of patients requiring Norwood palliation as newborns may become candidates for eventual biventricular repair with low risk. Typically, these patients have a $z$-score for the mitral valve of greater than -3 , and a left ventricle of normal size. Recognition of candidates for biventricular repair during the neonatal period will permit immediate consideration for complete biventricular repair. Repair using the single stage, however, needs to be compared with the excellent results obtainable with the staged approach. ${ }^{76}$

Hybrid approaches and transcatheter palliation A variety of hybrid approaches and transcatheter therapeutic options have evolved and are available to help manage patients born with the syndrome. Some of these options allow for bridging to cardiac transplantation, or provide temporary relief of symptoms before undertaking more definitive and radical surgery at potentially lower risk. It is possible, in the future, that a baby with hypoplastic left heart syndrome might initially be palliated by transcatheter placement of a stent in the arterial duct, along with transcatheter application of bilateral pulmonary arterial bands. Surgery may then be no more than a single stage neoaortic construction and hemiFontan procedure, followed later by transcatheter completion of a lateral tunnel Fontan procedure with a covered stent, which may be fenestrated.

\section{Crossmap for therapeutic options related to bypoplastic left beart syndrome}

As we showed in the diagnostic section of the crossmap, what follows is the crossmap of the names for procedures related to the hypoplastic left heart syndrome. In Table 3, we show the names emerging from the version of the International Code derived from the nomenclature of the International Congenital Heart Surgery Nomenclature and Database Project, while in Table 4 we show the equivalent and crossmapped terms using the version of the International Code derived from the nomenclature of the European Paediatric Cardiac Code. 
Table 3. The European Association for Cardiothoracic Surgery - Society of Thoracic Surgeons derived version of the International Paediatric and Congenital Cardiac Code for Procedures related to Hypoplastic Left Heart Syndrome.

\section{Norwood (Stage 1)}

Norwood (Stage 1)

Norwood (Stage 1), Neoaortic construction using arch augmentation with patch

Norwood (Stage 1), Neoaortic construction using arch augmentation with patch, Patch of entire arch undersurface

Norwood (Stage 1), Neoaortic construction using arch augmentation with patch, Posterior arch direct anastomosis with anterior arch patch

Norwood (Stage 1), Neoaortic construction using complete circumferential conduit interposition between native transected proximal pulmonary artery and aortic arch

Norwood (Stage 1), Neoaortic construction using native tissue and direct anastomosis (without patch such as homograft material, prosthetic material or pericardium)

\section{Norwood (Stage 1) Modifiers}

Norwood (Stage 1)-modifier, ASD enlargement

Norwood (Stage 1)-modifier, ASD enlargement, Via atrial pursestring

Norwood (Stage 1)-modifier, ASD enlargement, Via separate atriotomy

Norwood (Stage 1)-modifier, Atrial septectomy

Norwood (Stage 1)-modifier, Atrial septectomy not done

Norwood (Stage 1)-modifier, Atrial septectomy, Via atrial pursestring

Norwood (Stage 1)-modifier, Atrial septectomy, Via separate atriotomy

Norwood (Stage 1)-modifier, Isthmus excision not done

Norwood (Stage 1)-modifier, Isthmus excision performed

Norwood (Stage 1)-modifier, Native ascending aortic reconstructive technique, Incision of native ascending aorta down to near level of native transected proximal pulmonary artery

Norwood (Stage 1)-modifier, Native ascending aortic reconstructive technique, Neoaortic construction using ascending aortic transection

Norwood (Stage 1)-modifier, Native ascending aortic reconstructive technique, Neoaortic construction using ascending aortic transection,

PA transection and side to side (double barrel type) anastomosis

Norwood (Stage 1)-modifier, Native ascending aortic reconstructive technique, Neoaortic construction using ascending aortic transection,

Proximal ascending aortic implantation with end to side anastomosis

Norwood (Stage 1)-modifier, Native ascending aortic reconstructive technique, No incision of ascending aorta

Norwood (Stage 1)-modifier, Source of pulmonary blood flow, Neo-aorta to PA anastomosis + intervening fenestrated baffle

Norwood (Stage 1)-modifier, Source of pulmonary blood flow, "Sano" modification (RV to PA valveless conduit)

Norwood (Stage 1)-modifier, Source of pulmonary blood flow, "Sano" modification (RV to PA valveless conduit),

No proximal shunt patch + Distal shunt patch

Norwood (Stage 1)-modifier, Source of pulmonary blood flow, "Sano" modification (RV to PA valveless conduit), No proximal shunt

patch + No distal shunt patch

Norwood (Stage 1)-modifier, Source of pulmonary blood flow, "Sano" modification (RV to PA valveless conduit), Proximal shunt patch + Distal shunt patch

Norwood (Stage 1)-modifier, Source of pulmonary blood flow, "Sano" modification (RV to PA valveless conduit), Proximal shunt

patch + No distal shunt patch

Norwood (Stage 1)-modifier, Source of pulmonary blood flow, "Sano" modification-with valve (RV to PA valved conduit)

Norwood (Stage 1)-modifier, Source of pulmonary blood flow, "Sano" modification-with valve (RV to PA valved conduit),

No proximal shunt patch + Distal shunt patch

Norwood (Stage 1)-modifier, Source of pulmonary blood flow, "Sano" modification-with valve (RV to PA valved conduit),

No proximal shunt patch + No distal shunt patch

12.10 .00

12.10 .11

12.10 .12

12.10 .19

12.10 .06

12.30 .24

12.01 .93

12.01 .94

12.01 .43

$12.01 .43, \mathrm{Q} 5.81 .01$

12.01 .91

12.01 .92

Q5.10.52

Q5.10.51

Q5.10.5

Q5.10.54

Q5.10.5

Q5.10.56

Q5.10.57

12.10 .13

12.06 .43

$12.06 .43+$ Q5 .95 .05

$12.06 .43+$ Q5.95.08

$12.06 .43+\mathrm{Q} 5.95 .07$

$12.06 .43+$ Q5 595.06

12.06 .50

12.06.50+ Q5.95.05

$12.06 .50+$ Q5.95.08 
Table 3. The European Association for Cardiothoracic Surgery - Society of Thoracic Surgeons derived version of the International Paediatric and Congenital Cardiac Code for Procedures related to Hypoplastic Left Heart Syndrome (Continued)

Norwood (Stage 1)-modifier, Source of pulmonary blood flow, "Sano" modification-with valve

$12.06 .50+\mathrm{Q} 5.95 .07$

(RV to PA valved conduit), Proximal shunt patch + Distal shunt patch

Norwood (Stage 1)-modifier, Source of pulmonary blood flow, "Sano" modification-with valve (RV to PA valved conduit),

$12.06 .50+\mathrm{Q} 5.95 .06$

Proximal shunt patch + No distal shunt patch

Norwood (Stage 1)-modifier, Source of pulmonary blood flow, Shunt - systemic artery to pulmonary artery

Norwood (Stage 1)-modifier, Source of pulmonary blood flow, Stage $1+$ Cavopulmonary anastomosis

2.31 .30

12.31 .70

Norwood (Stage 1)-modifier, With circulatory arrest

Norwood (Stage 1)-modifier, With circulatory arrest, Circulatory arrest to brain

Norwood (Stage 1)-modifier, With circulatory arrest, Circulatory arrest to brain, With cardiac perfusion

Norwood (Stage 1)-modifier, With circulatory arrest, Circulatory arrest to brain, With cardiac perfusion and descending aortic perfusion

Q5.41.01

Q5.41.21

Q5.41.22

Q5.41.24

Q5.41.23

Norwood (Stage 1)-modifier, With circulatory arrest, Circulatory arrest to brain, With descending aortic perfusion

Norwood (Stage 1)-modifier, With circulatory arrest, Complete circulatory arrest

Norwood (Stage 1)-modifier, Without circulatory arrest

Norwood (Stage 1)-modifier, Without circulatory arrest, Arterial cannula into innominate artery

Norwood (Stage 1)-modifier, Without circulatory arrest, Asou/Pigula technique (arterial cannulas into BTS open end)

Norwood (Stage 1)-modifier, Without circulatory arrest, Imoto technique (2 arterial cannulas: 1 into BTS and 1 into descending thoracic aorta)

Norwood (Stage 1)-modifier, Without circulatory arrest, Tchervenkov technique (arterial cannula into

PDA perfusing head and body via RPA and BTS)

Q5.41.20

Q5.41.02

Q5.41.03

Q5. 41.04

Q5.41.05

Q5.41.06

Types of Cardiac Transplantation

Transplant, Heart

Transplant, Heart and lung(s)

Transplant, Heart and lung(s), Heart/double lung

Transplant, Heart and lung(s), Heart/left lung

Transplant, Heart and lung(s), Heart/right lung

Transplant, Heart, Orthotopic: allograft

Transplant, Heart, Orthotopic: xenograft

Transplant, Heart-modifier, ABO incompatible transplant

Transplant, Heart-modifier, ABO incompatible transplant, Inadvertent ABO incompatible transplant

Transplant, Heart-modifier, ABO incompatible transplant, Planned ABO incompatible transplant

Transplant, Heart-modifier, Bicaval anastomosis

Transplant, Heart-modifier, Right atrial cuff anastomosis

Transplant, Heart-modifier, With donor $=$ Brain dead dono

Transplant, Heart-modifier, With donor $=$ Brain dead donor, Beating heart donor

Transplant, Heart-modifier, With donor = Brain dead donor, Non-beating heart donor (Cadaveric donor)

Transplant, Heart-modifier, With donor = Live donor as part of domino transplant

Transplant, Heart-modifier, With intracardiac repair

Transplant, Heart-modifier, With intracardiac repair, ASD repair

Transplant, Heart-modifier, With intracardiac repair, ASD repair, PFO

Transplant, Heart-modifier, With intracardiac repair, VSD repair

Transplant, Heart-modifier, With intracardiac repair, With valvuloplasty

Transplant, Heart-modifier, With intracardiac repair, With valvuloplasty, Aortic valve valvuloplasty

Transplant, Heart-modifier, With intracardiac repair, With valvuloplasty, Mitral valve valvuloplasty

Transplant, Heart-modifier, With intracardiac repair, With valvuloplasty, Pulmonic valve valvuloplasty

Transplant, Heart-modifier, With intracardiac repair, With valvuloplasty, Tricuspid valve valvuloplasty

12.37 .01

12.32 .13

$12.37 .01,12.37 .20$

$12.37 .01,12.37 .22$

$12.37 .01,12.37 .21$

12.37 .02

12.37 .48

12.37 .06

$12.37 .06+\mathrm{Q} 1.91 .02$

$12.37 .06+\mathrm{Q} 1.91 .01$

Q5.37.84

Q5.37.85

12.37.41

12.37 .44

12.37 .42

12.37 .09

Q5.37.81

Q5.37.81, 12.01.00

Q5.37.81, 12.01.58

Q5.37.81, 12.08.01

Q5.37.81, 12.43.50

Q5.37.81, 12.16.11

Q5.37.81, 12.03.03

Q5.37.81, 12.13.11

Q5.37.81, 12.02.02 
Transplant-modifier for sequence of transplant, Retransplant, 3rd transplant (2nd retransplant)

Transplant-modifier for sequence of transplant, Retransplant, 4th transplant (3rd retransplant)

\section{Hypoplastic Left Heart Syndrome Biventricular Repair}

HLHS biventricular repair

HLHS biventricular repair, After a Norwood (Stage 1)

HLHS biventricular repair, After a Norwood (Stage 1), Aortic arch repair

HLHS biventricular repair, After a Norwood (Stage 1), Aortic coarctation repair

HLHS biventricular repair, After a Norwood (Stage 1), Aortic valve repair

HLHS biventricular repair, After a Norwood (Stage 1), Aortic valve replacement

HLHS biventricular repair, After a Norwood (Stage 1), Conduit insertion RV to PA + Intraventricular tunnel LV to Neoaorta

HLHS biventricular repair, After a Norwood (Stage 1), Conduit insertion RV to PA + Intraventricular tunnel LV to Neoaorta + Arch reconstruction

HLHS biventricular repair, After a Norwood (Stage 1), Mitral valve repair

HLHS biventricular repair, After a Norwood (Stage 1), Mitral valve replacement

HLHS biventricular repair, After a Norwood (Stage 1), Septal defect repair - ASD

HLHS biventricular repair, After a Norwood (Stage 1), Septal defect repair - ASD and VSD

HLHS biventricular repair, After a Norwood (Stage 1), Septal defect repair - VSD

HLHS biventricular repair, Without prior Norwood (Stage 1)

HLHS biventricular repair, Without prior Norwood (Stage 1), Aortic arch repair

HLHS biventricular repair, Without prior Norwood (Stage 1), Aortic coarctation repair

HLHS biventricular repair, Without prior Norwood (Stage 1), Aortic valve repair

HLHS biventricular repair, Without prior Norwood (Stage 1), Aortic valve replacement

HLHS biventricular repair, Without prior Norwood (Stage 1), Conduit insertion right ventricle to pulmonary artery +

Intraventricular tunnel left ventricle to neoaorta

HLHS biventricular repair, Without prior Norwood (Stage 1), Conduit insertion right ventricle to pulmonary artery + Intraventricular tunnel

$12.10 .16,12.18 .30$

$12.10 .16,12.18 .26$

$12.10 .16,12.16 .60$

$12.10 .16,12.16 .21$

12.10 .17

$12.10 .17,12.10 .30$

$12.10 .16,12.03 .90$

$12.10 .16,12.03 .11$

$12.10 .16,12.01 .00$

12.10.16, 12.01.00

12.08.01

$12.10 .16,12.08 .01$

12.10.21

$12.10 .21,12.18 .30$

$12.10 .21,12.18 .26$

$12.10 .21,12.16 .60$

$12.10 .21,12.16 .21$

12.10 .08

left ventricle to neoaorta + Arch reconstruction (Rastelli and Norwood type arch reconstruction) (Yasui)

HLHS biventricular repair, Without prior Norwood (Stage 1), Direct right ventricle to pulmonary artery anastomosis + Intraventricular

12.10 .10

tunnel left ventricle to neoaorta + Arch reconstruction (REV and Norwood type arch reconstruction)

HLHS biventricular repair, Without prior Norwood (Stage 1), Direct right ventricle to pulmonary artery anastomosis +

Intraventricular tunnel left ventricle to neoaorta + Arch reconstruction (REV and Norwood type arch reconstruction), With Lecompte maneuver

HLHS biventricular repair, Without prior Norwood (Stage 1), Direct right ventricle to pulmonary artery anastomosis +

Intraventricular tunnel left ventricle to neoaorta + Arch reconstruction (REV and Norwood type arch reconstruction), Without Lecompte maneuver

HLHS biventricular repair, Without prior Norwood (Stage 1), Endocardial fibrosis peeling (Endocardiectomy)

HLHS biventricular repair, Without prior Norwood (Stage 1), Endocardial fibrosis peeling (Endocardiectomy), Left ventricular endocardiectomy

HLHS biventricular repair, Without prior Norwood (Stage 1), Mitral valve repair

HLHS biventricular repair, Without prior Norwood (Stage 1), Mitral valve replacement

HLHS biventricular repair, Without prior Norwood (Stage 1), Ross-Konno

HLHS biventricular repair, Without prior Norwood (Stage 1), Septal defect repair 
Table 3. The European Association for Cardiothoracic Surgery - Society of Thoracic Surgeons derived version of the International Paediatric and Congenital Cardiac Code for Procedures related to Hypoplastic Left Heart Syndrome (Continued)

HLHS biventricular repair, Without prior Norwood (Stage 1), Septal defect repair - ASD

HLHS biventricular repair, Without prior Norwood (Stage 1), Septal defect repair - ASD and VSD

HLHS biventricular repair, Without prior Norwood (Stage 1), Septal defect repair - VSD

Hypoplastic Left Heart Syndrome Hybrid Approaches and Transcatheter Palliation

HLHS Hybrid "Stage 1"

HLHS Hybrid "Stage 1", Application of RPA \& LPA bands

HLHS Hybrid "Stage 1", Application of RPA \& LPA bands (Prior stent placement in arterial duct [PDA])

HLHS Hybrid "Stage 1", Application of RPA \& LPA bands (Prior stent placement in arterial duct [PDA]),

PA bands placed internally via transcatheter technique (Boucek)

HLHS Hybrid "Stage 1", Application of RPA \& LPA bands (Prior stent placement in arterial duct [PDA]), PA bands placed surgically

HLHS Hybrid "Stage 1", Application of RPA \& LPA bands, PA bands placed internally via transcatheter technique (Boucek)

HLHS Hybrid "Stage 1", Application of RPA \& LPA bands, PA bands placed surgically

HLHS Hybrid "Stage 1", Stent placement in arterial duct (PDA)

HLHS Hybrid "Stage 1", Stent placement in arterial duct (PDA) and application of RPA \& LPA bands

HLHS Hybrid "Stage 1", Stent placement in arterial duct (PDA) and application of RPA \& LPA bands,

PA bands placed internally via transcatheter technique (Boucek)

HLHS Hybrid "Stage 1", Stent placement in arterial duct (PDA) and application of RPA \& LPA bands, PA bands placed surgically

HLHS Comprehensive "Stage 2"

HLHS Comprehensive "Stage 2", Damus-Kaye-Stansel (DKS) procedure and Aortic arch repair and Superior Cavopulmonary anastomosis

(Norwood [Stage 1] + Glenn]) and PA Debanding

HLHS Comprehensive "Stage 2", Damus-Kaye-Stansel (DKS) procedure and Aortic arch repair and Superior Cavopulmonary anastomosis (Norwood [Stage 1] + Glenn]) and PA Debanding and Atrial septectomy
$12.01 .21,12.10 .05$

$12.01 .21,12.10 .05$

12.08 .01

$12.10 .21,12.08 .01$

12.20.21

12.20.21, 12.14.19

12.20.21, 12.14.19,

$12.10 .14+\mathrm{Q} 5.81 .17$

12.20.21, 12.15.42

$12.10 .14+$ Q5.81.17

12.20.21, 12.14.19,

$12.10 .14+\mathrm{Q} 5.81 .17$

$12.20 .21,12.15 .42$

12.20.21, 12.14.19

$12.20 .21,12.10 .14$

$12.20 .21,12.10 .04$

12.20.21, 12.10.14,

12.15 .42

$12.20 .21,12.10 .04$

12.20 .22

$12.09 .03,12.18 .30$,

$12.31 .72,12.15 .60$

$12.09 .03,12.18 .30,12.31 .72$ $12.15 .60,12.01 .43$

Abbreviations as for Table 1 and PA, pulmonary artery 
Norwood (Stage 1)

Norwood type procedure,

Norwood type procedure: neoaortic construction using patch,

12.10 .00

Norwood type procedure: neoaortic construction using patch to entire undersurface of arch,

12.10 .01

Norwood type procedure: neoaortic construction with posterior direct arch anastomosis \& anterior augmentation patch,

12.10 .11

12.10 .12

Norwood type procedure: neoartic construction with direct anastomosis \& native tissue only,

12.10 .16

The following corresponding terms with numerical codes would then be added to the initial Norwood type procedure code:

Interatrial communication (“ASD”) enlargement - surgical,

12.10 .06

Interatrial communication (“ASD”) enlargement via atrial purse string,

12.30 .24

Interatrial communication ("ASD”) enlargement via separate atriotomy,

Atrial septectomy,

Atrial septectomy via atrial purse string,

Atrial septectomy via separate atriotomy,

Atrial septectomy, - procedure not performed

Creation of neoaorta to pulmonary artery anastomosis + intervening fenestrated baffle,

Right ventricle to pulmonary artery valveless conduit construction ("Sano"),

Right ventricle to pulmonary artery valveless conduit construction ("Sano"), - with patch augmentation of distal conduit,

Right ventricle to pulmonary artery valveless conduit construction ("Sano"), - with patch augmentation of proximal conduit,

Right ventricle to pulmonary artery valveless conduit construction ("Sano"), - with patch augmentation of proximal + distal conduit,

Right ventricle to pulmonary artery valveless conduit construction ("Sano"), - without patch augmentation of conduit,

RV to pulmonary artery valved conduit construction,

$\mathrm{RV}$ to pulmonary artery valved conduit construction, - with patch augmentation of distal conduit,

$\mathrm{RV}$ to pulmonary artery valved conduit construction, - with patch augmentation of proximal conduit,

$\mathrm{RV}$ to pulmonary artery valved conduit construction, - with patch augmentation of proximal + distal conduit,

RV to pulmonary artery valved conduit construction, - without patch augmentation of conduit,

Systemic-to-pulmonary arterial shunt procedure,

Caval vein to pulmonary artery anastomosis,

12.01 .93

12.01 .94

12.01 .43

12.01 .91

12.01 .92

$12.01 .43+\mathrm{Q} 5.81 .01$

12.10 .13

12.06 .43

12.06.43 + Q5.95.05

$12.06 .43+$ Q5 .95 .06

$12.06 .43+$ Q5 .95 .07

$12.06 .43+\mathrm{Q} 5.95 .08$

12.06 .50

$12.06 .50+Q 5.95 .05$

$12.06 .50+$ Q 5.95 .06

$12.06 .50+\mathrm{Q} 5.95 .07$

$12.06 .50+$ Q5.95.08

12.31 .30

12.31 .70

In contrast to the above terms that have their own entries, which are not tied to hypoplastic left heart syndrome surgery as such, the following corresponding qualifier

terms with numerical codes in may then be appended onto the initial Norwood type procedure code, as needed. The structure of the European Paediatric Cardiac

Code in this regard has been described previously. ${ }^{73}$

- with isthmus excision,

- without isthmus excision,

- with native ascending aorta incision to near level of transected proximal pulmonary trunk,

- using ascending aortic transection,

- using ascending aorta + pulmonary trunk transection \& side to side (double barrel) anastomosis,

- using ascending aortic transection \& proximal aortic implantation (end to side),

- without ascending aorta incision,

- with circulatory arrest,

- with circulatory arrest: complete,

- with circulatory arrest to brain,

- with circulatory arrest to brain with cardiac perfusion, 
Table 4. The Association for European Paediatric Cardiology derived version of the International Paediatric and Congenital Cardiac Code for the Procedures related to Hypoplastic Left Heart Syndrome (Continued).

- with circulatory arrest with descending aorta perfusion,

- with circulatory arrest to brain with cardiac + descending aorta perfusion,

- without circulatory arrest,

- without circulatory arrest: arterial cannula into innominate artery,

- without circulatory arrest: arterial cannula into open end of shunt (Asou / Pigula),

- without circulatory arrest: arterial cannulas into open end of shunt + descending aorta (Imoto),

- without circulatory arrest: arterial cannulas into arterial duct (head) \& via right pulmonary artery to shunt (body) (Tchervenkov),

Q5.41.23
Q5 41.24
Q5.41.02
Q5.41.03
Q5.41.04
Q5.41.05
Q5 41.06

Types of Cardiac transplantation (including qualifier terms)

Heart transplant,

Transplantation of heart - orthotopic allotransplant,

Transplantation of heart - ABO incompatible donor,

Transplantation of heart - ABO incompatible donor, - intentional,

Transplantation of heart - ABO incompatible donor, - inadvertent,

Xenotransplant of heart - orthotopic,

Transplantation of heart and lung(s),

Double lung transplant,

Single right lung transplant,

Single left lung transplant,

Transplant from brain dead donor,

Transplant from brain dead beating heart donor,

Transplant from brain dead non-beating heart donor,

Removal of heart from live donor (domino transplant),

Initial transplant,

Retransplant,

First retransplant,

Second retransplant,

Third retransplant,

Fourth or more retransplant,

- with transverse arch augmentation,

- without transverse arch augmentation,

- bicaval anastomosis,

- right atrial cuff anastomosis,

- with intracardiac repair,

Hypoplastic Left Heart Syndrome Biventricular Repair

Hypoplastic left heart biventricular repair,

Hypoplastic left heart biventricular repair (without prior Norwood type procedure): left ventricle-neoaorta tunnel + right ventricle to pulmonary artery conduit,

Hypoplastic left heart bi-ventricular repair: left ventricle-neoaorta tunnel + right ventricle to pulmonary artery conduit + arch reconstruction (Rastelli-Norwood) (Yasui),

Hypoplastic left heart bi-ventricular repair: left ventricle-neoaorta tunnel + direct right ventricle to pulmonary trunk anastomosis + arch reconstruction (REV-Norwood),
12.37 .01

12.37 .02

12.37 .06

$12.37 .06+\mathrm{Q} 1.91 .01$

$12.37 .06+\mathrm{Q} 1.91 .02$

12.37 .48

12.32 .13

12.37 .20

12.37 .21

12.37 .22

12.37 .41

12.37 .44

12.37.09

12.37 .51

12.37 .57

12.37 .52

12.37 .53

12.37 .54

12.37 .55

Q5.37.82

Q5.37.83

Q5.37.84

Q5.37.85

Q5.37.81

12.10 .05

12.10 .08

12.10 .10

12.10 .22 
Hypoplastic left heart bi-ventricular repair: left ventricle-neoaorta tunnel + direct right ventricle to pulmonary trunk anastomosis + arch reconstruction (with

Lecompte manoeuvre) (REV-Norwood),

Hypoplastic left heart bi-ventricular repair: left ventricle-neoaorta tunnel + direct right ventricle to pulmonary trunk anastomosis + arch reconstruction (without

e) (REV-Norwood)

Hypoplastic left heart biventricular repair (without prior Norwood type procedure),

Hypoplastic left heart biventricular repair after Norwood type procedure,

Hypoplastic left heart biventricular repair after Norwood type procedure: left ventricle-neoaorta tunnel + right ventricle to pulmonary artery conduit,

Hypoplastic left heart bi-ventricular repair after Norwood type procedure: left ventricle-neoaorta tunnel + right ventricle to pulmonary artery conduit + arch

reconstruction,

The following equivalent terms with numerical codes can then be added to the above items as appropriate:

Aortic arch repair

Coarctation of aorta repair,

Valve leaflet(s) repair (valvoplasty),

Aortic valve repair,

Aortic cusp(s) repair (valvoplasty),

Aortic valvar replacement,

Mitral valve repair,

Mitral leaflet (valvoplasty) procedure,

Mitral valvar replacement,

Tricuspid leaflet (valvoplasty) procedure,

Pulmonary cusp(s) repair (valvoplasty)

Septal defect closure,

Interatrial communication closure,

Patent foramen ovale (PFO) closure,

VSD closure,

Endocardiectomy procedure,

Left ventricular endocardiectomy,

Ross-Konno procedure,

\section{Hypoplastic Left Heart Syndrome Palliation (surgical and transcatheter)}

Hypoplastic left heart syndrome hybrid approach (transcatheter \& surgery),

Hypoplastic left heart syndrome hybrid approach (transcatheter \& surgery): stage 1,

Application of right \& left pulmonary arterial bands,

Stent placement in arterial duct (PDA),

Stent placement in arterial duct (PDA), - preceding,

Right + left pulmonary artery flow restriction using transcatheter implanted devices,

Damus-Kaye-Stansel type procedure: pulmonary trunk to aorta end/side anastomosis,

Superior caval vein to pulmonary artery anastomosis,

Abbreviations as for Table 1 


\section{Summary}

During the process of creation of a bidirectional crossmap between the system emerging, on the one hand, from the initiative sponsored by the Congenital Heart Committees of the European Association for Cardio-Thoracic Surgery and the Society of Thoracic Surgeons, ${ }^{75}$ and on the other hand, from that formulated by the Coding Committee of the European Association for Paediatric Cardiology, ${ }^{73,74}$ the Nomenclature Working Group has successfully created the International Paediatric and Congenital Cardiac Code. As would be expected, during the process of crossmapping it became clear that, for most lesions, the European Paediatric Cardiac Code was more complete in its description of the diagnoses, while the International Congenital Heart Surgery Nomenclature and Database Project was more complete in its description of the procedures. Interestingly, for hypoplastic left heart syndrome, the surgical nomenclature proved suboptimal in its description of therapeutic options, in part because a huge amount of time had been spent by the surgical committees debating the diagnostic definition and classification of hypoplastic left heart syndrome. During the meetings of the International Congenital Heart Surgery Nomenclature and Database Project, a separate session was arranged specifically to establish the nomenclature for the syndrome. This session focused on debating the diagnostic definitions and existing classifications. The recent additional debates by the Nomenclature Working Group have allowed for further clarification of these diagnostic definitions and classifications, and have resulted in provision of a more comprehensive and accurate nomenclature for the diagnoses and procedures related to patients born with the hypoplastic left heart syndrome. This process ${ }^{2-7}$ of crossmapping major nomenclature systems for the multiple lesions making up the hypoplastic left heart syndrome exemplifies the entire efforts of the Nomenclature Working Group to create a comprehensive and all-inclusive international system for the naming of paediatric and congenital cardiac disease, the International Paediatric and Congenital Cardiac Code.

The comprehensive nomenclature now offered by the Nomenclature Working Group for the diagnoses and procedures related to hypoplastic left heart syndrome and related malformations demonstrates the value of The International Paediatric and Congenital Cardiac Code produced by this committee. Although names and classification for paediatric and congenital cardiac disease will continue to evolve over time, we are now closer than ever to reaching uniform international agreement and standardization. The International Paediatric and Congenital Cardiac Code can be downloaded from the Internet, free of charge, at www.ipccc.net.

\section{References}

1. Tchervenkov CI, Jacobs ML, Tahta SA. Congenital heart surgery nomenclature and database project: Hypoplastic left heart syndrome. Ann Thorac Surg 2000; 69: S170-179.

2. Franklin RCG, Jacobs JP, Tchervenkov CI, Béland M. Report from the Executive of The International Working Group for Mapping and Coding of Nomenclatures for Paediatric and Congenital Heart Disease: Bidirectional Crossmap of the Short Lists of the European Paediatric Cardiac Code and the International Congenital Heart Surgery Nomenclature and Database Project. Cardiol Young 2002; 12 (Suppl 2): 18-22.

3. Franklin RCG, Jacobs JP, Tchervenkov CI, Béland M. European Paediatric Cardiac Code Short List crossmapped to STS/EACTS Short List with ICD-9 \& ICD-10 crossmapping. Cardiol Young 2002; 12 (Suppl 2): 23-49.

4. Franklin RCG, Jacobs JP, Tchervenkov CI, Béland M. STS/ EACTS Short List mapping to European Paediatric Cardiac Code Short List with ICD-9 \& ICD-10 crossmapping. Cardiol Young, 2002; 12 (Suppl 2): 50-62.

5. Béland M, Jacobs JP, Tchervenkov CI, Franklin RCG. The International Nomenclature Project for Paediatric and Congenital Heart Disease: Report from the Executive of The International Working Group for Mapping and Coding of Nomenclatures for Paediatric and Congenital Heart Disease. Cardiol Young 2002; 12: 425-430.

6. Franklin RCG, Jacobs JP, Tchervenkov CI, Béland M. The International Nomenclature Project for Pediatric and Congenital Heart Disease: Bidirectional Crossmap of the Short Lists of the European Paediatric Cardiac Code and the International Congenital Heart Surgery Nomenclature and Database Project. Cardiol Young 2002; 12: 431-435.

7. Béland MJ, Franklin RCG, Jacobs JP, Tchervenkov CI, Aiello VD, Colan SD, Gaynor JW, Krogmann ON, Kurosawa H, Maruszewski B, Stellin G, Weinberg PM. Update from The International Working Group for Mapping and Coding of Nomenclatures for Paediatric and Congenital Heart Disease. Cardiol Young 2004; 14: 225-229.

8. Gehrmann J, Krasemann T, Kehl HG, Vogt J. Hypoplastic left heart syndrome. The first description of the pathophysiology in 1851; Translation of a Publication by Dr. Bardeleben From Giessen, Germany. Chest 2001; 120: 1368-1371.

9. Lev M. Pathologic anatomy and interrelationship of hypoplasia of the aortic tract complexes. Lab Invest 1952; 1: 61-70.

10. Lev M. Some newer concepts of the pathology of congenital heart disease. Med Clin North Am 1966; 50: 3-14.

11. Bharati S, Lev M. The surgical anatomy of hypoplasia of aortic tract complex. J Thorac Cardiovasc Surg 1984; 88: 97-101.

12. Noonan JA, Nadas AS. The hypoplastic left heart syndrome. An analysis of 101 cases. Pediatr Clin North Am 1958; 5: 1029-1056.

13. Currarino G, Edwards FK, Kaplan S. Hypoplasia of the left heart complex. AMA J Dis Chil 1959; 97: 839-844.

14. Norwood WI, Kirklin JK, Sanders SP. Hypoplastic left heart syndrome. Experience with palliative surgery. Am J Cardiol 1980; 45: 87-91.

15 Norwood WI, Lang P, Castaneda AR, Campbell DN. Experience with operations for hypoplastic left heart syndrome. J Thorac Cardiovasc Surg 1981; 82: 511-519.

16. Doty DB, Marvin WJ, Schieken RM, Lauer RM. Hypoplastic left heart syndrome. Successful palliation with a new operation. J Thorac Cardiovasc Surg 1980; 80: 148-152.

17. Saied A, Folger GM. Hypoplastic left heart syndrome. Clinicopathologic and hemodynamic correlation. Am J Cardiol 1972; 29: 190-196. 
18. Deely WJ, Ehlers KH, Levin AR, Engle MA. Hypoplastic left heart syndrome. Anatomic, physiologic, and therapeutic considerations. Am J Dis Child 1971; 121: 168-175.

19. Tchervenkov CI, Béland MJ, Latter DA, Dobell ARC. Norwood operation for univentricular heart with subaortic stenosis in the neonate. Ann Thorac Surg 1990; 50: 822-825.

20. Jacobs ML, Rychik J, Murphy JD, Nicholson SC, Steven JM, Norwood WI. Results of Norwood's operation for lesions other than hypoplastic left heart syndrome. J Thorac Cardiovasc Surg 1995; 110: 1555-1562.

21. Kanter KR, Miller BE, Cuadrado AG, Vincent RN. Successful application of the Norwood procedure for infants without hypoplastic left heart syndrome. Ann Thorac Surg 1995; 59: 301-304.

22. Kirklin JW, Barratt-Boyes BG. Coarctation of the aorta and interrupted aortic arch. In: Kirklin JW, Barratt-Boyes BG (eds). Cardiac Surgery, 2nd ed. Churchill Livingstone, New York, 1993, pp 1269-1270.

23. Page DA, Levine MM. Left ventricular growth in a patient with critical coarctation of the aorta and hypoplastic left ventricle. Pediatr Cardiol 1995; 16: 176-178.

24. Kovalchin JP, Brook MM, Silverman NH. Growth of the hypoplastic left ventricle? Pediatr Cardiol 1997; 18: 451-452.

25. Minich LL, Tani LY, Hawkins JA, Shaddy RE. Possibility of postnatal left ventricular growth in selected infants with nonapexforming left ventricles. Am Heart J 1997; 133: 570-574.

26. Serraf A, Piot JD, Bonnet N, et al. Biventricular repair approach in ducto-dependent neonates with hypoplastic but morphologically normal left ventricle. J Am Coll Cardiol 1999; 33: 827-834.

27. Tani LY, Minich LL, Pagotto LT, Shaddy RE, McGough EC, Hawkins JA. Left heart hypoplasia and neonatal aortic arch obstruction. J Thorac Cardiovasc Surg 1999; 118: 81-86.

28. Alboliras ET, Mavroudis C, Pahl E, Gidding SS, Backer CL, Rocchini AP. Left ventricular growth in selected hypoplastic left ventricles. Ann Thorac Surg 1999; 68: 549-555.

29. Tchervenkov CI, Tahta SA, Jutras L, Béland MJ. Biventricular repair in neonates with hypoplastic left heart complex. Ann Thorac Surg 1998; 66: 1350-1357.

30. Shone JD, Sellers RD, Anderson RG, Adams P, Lillehei CW, Edwards JE. The developmental complex of "parachute mitral valve", supravalvar ring of left atrium, subaortic stenosis, and coarctation of the aorta. Am J Cardiol 1963; 11: 714-725.

31. Moodie DS, Gallen WJ, Friedberg DZ. Congenital aortic atresia. Report of long survival and some speculation about surgical approaches. J Thorac Cardiovasc Surg 1972; 63: 726-731.

32. Koutchoukos NT, Blackstone EH, Doty DB, Hanley FL, Karp RB. Aortic atresia and other forms of hypoplastic left heart physiology. In: Koutchoukos NT, Blackstone EH, Doty DB, Hanley FL, Karp RB (eds). Kirklin/Barratt-Boyes Cardiac Surgery, 3rd ed. Vol. 2, Churchill Livingstone, Philadelphia, 2003, pp $1377-1400$.

33. Dorland's Illustrated Medical Dictionary Edition 28. W.B. Saunders Company. Philadelphia, PA 1994.

34. Rhodes LA, Colan SD, Perry SB, Jonas RA, Sanders SP. Predictors of survival in neonates with critical aortic stenosis. Circulation 1991; 84: 2325-2335.

35. Lofland GK, McCrindle BW, Williams WG, et al. Critical aortic stenosis in the neonate: a multi-institutional study of management, outcomes, and risk factors. Congenital Heart Surgeons Society. J Thorac Cardiovasc Surg 2001; 121: 10-27.

36. Aiello VD, Ho SY, Anderson RH, Thiene G. Morphologic features of the hypoplastic left heart syndrome - a reappraisal. Ped Pathol 1990; 10: 931-943.

37. Weinberg PM, Chin AJ, Murphy JD, Pigott JD, Norwood WI. Postmortem echocardiography and tomographic anatomy of hypoplastic left heart syndrome after palliative surgery. Am J Cardiol 1986; 58: 1228-1232.
38. Norwood WI, Lang P, Hansen DD. Physiologic repair of aortic atresia-hypoplastic left heart syndrome. N Engl J Med 1983; 308: 23-26.

39. Bailey LL, Nehlsen-Cannarella SL, Doroshow RW, et al. Cardiac allotransplantation in newborns as therapy for hypoplastic left heart syndrome. N Engl J Med 1986; 315: 949-951.

40. Castañeda AR, Jonas RA, Mayer JE, Jr, Hanley FL. Hypoplastic left heart syndrome. In: Castañeda AR, Jonas RA, Mayer Jr JE, Hanley FL (eds). Cardiac surgery of the neonate and infant. WB Saunders Co, Philadelphia, 1994, pp 363-385.

41. Austin EH, Jonas RA, Mayer Jr JE, et al. Aortic atresia with normal left ventricle. J Thorac Cardiovasc Surg 1989; 97: 392-395.

42. Starnes VA, Griffin ML, Pitlick PT, et al. Current approach to hypoplastic left heart syndrome. Palliation, transplantation or both? J Thorac Cardiovasc Surg 1992; 104: 189-195.

43. Quintessenza JA, Morell VO, Jacobs JP. Achieving a balance in the current approach to the surgical treatment of hypoplastic left heart syndrome. Cardiol Young 2004; 14 (Suppl 1): I127-130.

44. Zahka KG, Spector M, Hanisch D. Hypoplastic left heart syndrome. Clin Perinatol 1993; 20: 145-155.

45. Storch TG. Passive euthanasia for hypoplastic left heart syndrome. Am J Dis Child 1992; 146: 1426.

46. Cayler GG, Smeloff EA, Miller GE. Surgical palliation of hypoplastic left side of the heart. N Engl J Med 1970; 282: 780-783.

47. Cayler G.G. Hypoplastic left heart syndrome. Am J Cardiol 1972; 30: 450 .

48. Doty DB, Knott HW. Hypoplastic left heart syndrome. J Thorac Cardiovasc Surg 1977; 74: 624-630.

49. Litwin SB, Van Praagh R, Bernhard WF. A palliative operation for certain infants with aortic arch interruption. Ann Thorac Surg 1972; 14: 369-375.

50. Mohri H, Horiuchi T, Haneda K, et al. Surgical treatment for hypoplastic left heart syndrome: case reports. J Thorac Cardiovasc Surg 1979; 78: 223-228.

51. Jacobs ML, Norwood WI. Hypoplastic left heart syndrome. In: Baue AE, Geha AS, Hammond GL, Laks H, Naunheim KS (eds). Glenn's Thoracic and Cardiovascular Surgery, 6th ed. Appleton \& Lange, Stamford, 1996, pp 1271-1281.

52. Giroud JM, Jacobs JP. Fontan's operation: evolution from a procedure to a process. Cardiol Young 2006; 16 (Suppl 1): SI67-SI71.

53. Bu'Lock FA, Strümper O, Jagtap R, et al. Surgery for infants with a hypoplastic systemic ventricle and severe outflow obstruction. Br Heart J 1995; 73: 456-461.

54. Fraser Jr CD, Mee RBB. Modified Norwood procedure for hypoplastic left heart syndrome. Ann Thorac Surg 1995; 60: S546-S549.

55. Bove EL, Lloyd TR. Staged reconstruction for hypoplastic left heart syndrome. Ann Surg 1996; 224: 387-395.

56. Malec E, Januszewska K, Kolcz J, Mroczek T. Right ventricle-topulmonary artery shunt versus modified Blalock-Taussig shunt in the Norwood procedure for hypoplastic left heart syndrome influence on early and late haemodynamic status. Eur J Cardiothorac Surg 2003; 23: 728-734.

57. Bartram U, Grünenfelder J, Van Praagh R. Causes of death after the modified Norwood procedure: a study of 122 postmortem cases. Ann Thorac Surg 1997; 64: 1795-1802.

58. Kishimoto H, Iio M, Kume Y, et al. The Norwood operation for hypoplastic left heart syndrome using a valved pericardial roll between the right ventricle and pulmonary artery. Cardiol Young 1993; 3 (Suppl 1): SI162.

59. Kishimoto H, Kawahira Y, Kawata H, Miura T, Iwai S, Mori T. The modified Norwood palliation on a beating heart. J Thorac Cardiovasc Surg 1999; 118: 1130-1132.

60. Imoto Y, Kado H, Shiokawa Y, Minami K, Yasui H. Experience with the Norwood procedure without circulatory arrest. J Thorac Cardiovasc Surg 2001; 122: 879-882. 
61. Sano S, Ishino K, Kawada M, et al. The modified Norwood operation for hypoplastic left heart syndrome: using right ventricle-topulmonary artery shunt. Cardiol Young 2001; 11 (Suppl 1): SI21.

62. Sano S. Outcome of right ventricle-to-pulmonary artery shunt in first stage palliation of hypoplastic left heart syndrome - Multi Institutional Study. Presented at the 2003 Society of Thoracic Surgeons Meeting.

63. Amodeo A, Galletti L, Marianeschi S, et al. Extracardiac Fontan operation for complex cardiac anomalies. J Thorac Cardiovasc Surg 1997; 114: 1020-1030.

64. Petrossian E, Reddy VM, McElhinney DB, et al. Early results of the extracardiac conduit Fontan operation. J Thorac Cardiovasc Surg 1999; 117: 688-696.

65. Norwood WI, Pizarro C. Presented at the 2002 Annual Congenital Heart Surgeons' Society Meeting, Chicago, Illinois, Monday, September 30, 2002.

66. Akintuerk H, Michel-Behnke I, Valeske K, et al. Stenting of the arterial duct and banding of the pulmonary arteries: basis for combined Norwood stage I and II repair in hypoplastic left heart. Circulation 2002; 105: 1099-1103.

67. Pizarro C, Murdison KA. Off pump palliation for hypoplastic left heart syndrome: surgical approach. Semin Thorac Cardiovasc Surg Pediatr Card Surg Annu 2005; 66-71.

68. Boucek MM, Mashburn C, Chan KC. Catheter-based interventional palliation for hypoplastic left heart syndrome. Semin Thorac Cardiovasc Surg Pediatr Card Surg Annu 2005; 72-77.
69. Lim DS, Peeler BB, Matherne GP, Kron IL, Gutgesell HP. Riskstratified approach to hybrid transcatheter-surgical palliation of hypoplastic left heart syndrome. Pediatr Cardiol 2005; August 17 (e-pub ahead of print).

70. Bailey LL, Gundry SR, Razzouk AJ, Wang N, Sciolaro CM, Chiavarelli M. Bless the babies. J Thorac Cardiovasc Surg 1993; 105: 805-815.

71. Norwood WI, Stellin GJ. Aortic atresia with interrupted aortic arch: reparative operation. J Thorac Cardiovasc Surg 1981; 81: 239-244.

72. Yasui H, Kado H, Nakano E, et al. Primary repair of interrupted aortic arch and severe aortic stenosis in neonates. J Thorac Cardiovasc Surg 1987; 93: 539-545.

73. Association for European Paediatric Cardiology. The European Paediatric Cardiac Code. Cardiol Young 2000; 10 (Suppl 1): SI1-SI146.

74. Franklin RCG. The European Paediatric Code Long List: structure and function - the first revision. Cardiol Young 2002; 12 (Suppl 2): SII9-SII17.

75. Mavroudis C, Jacobs JP. International Congenital Heart Surgery Nomenclature and Database Project. Ann Thorac Surg 2000; 69 (Suppl 4): S2-S17.

76. Pearl JM, Cripe LW, Manning PB. Biventricular repair after Norwood palliation. Ann Thorac Surg 2003; 75: 132-136; discussion 136-137. 